\title{
Resorcinol Crystallization from the Melt: A New Ambient Phase and New "Riddles"
}

\author{
Qiang Zhu, ${ }^{1}$ Alexander G. Shtukenberg, ${ }^{2}$ Damien J. Carter, ${ }^{3}$ Tang-Qing Yu, ${ }^{4}$ Jingxiang \\ Yang, ${ }^{2}$ Ming Chen, ${ }^{4}$ Paolo Raiteri, ${ }^{3}$ Artem R. Oganov, ${ }^{1}$ Boaz Pokroy, ${ }^{5}$ Iryna Polishchuk, ${ }^{5}$ \\ Peter J. Bygrave, ${ }^{6}$ Graeme M. Day, ${ }^{6}$ Andrew L. Rohl, ${ }^{3 *}$ Mark E. Tuckerman ${ }^{4,7 *}$ and Bart \\ $\mathrm{Kahr}^{2 *}$
}

${ }^{1}$ Department of Geosciences, Stony Brook University, Stony Brook, NY, 11794, USA ${ }^{2}$ Department of Chemistry and Molecular Design Institute, New York University, New York City, NY, 10003, USA

${ }^{3}$ Curtin Institute for Computation, Nanochemistry Research Institute and Department of Chemistry, Curtin University, P.O. Box U1987, Perth, 6845, Western Australia, Australia

${ }^{4}$ Department of Chemistry and Courant Institute, New York University, New York City, NY, 10003, USA

${ }^{5}$ Department of Materials Science and Engineering and the Russell Berrie Nanotechnology Institute, Technion Israel Institute of Technology, Haifa 32000, Israel ${ }^{6}$ School of Chemistry, University of Southampton, Highfield, Southampton, SO17 1BJ, UK

${ }^{7}$ New York University-East China Normal University Center for Computational Chemistry at NYU Shanghai, 3663 Zhongshan Road North, Shanghai 200062, China

ABSTRACT Structures of the $\alpha$ and $\beta$ phases of resorcinol, a major commodity chemical in the pharmaceutical, agrichemical, and polymer industries, were the first polymorphic pair of molecular crystals solved by X-ray analysis. It was recently stated that "no additional phases can be found under atmospheric conditions" (Druzbicki, K. et al. J. Phys. Chem. B 2015, 119, 1681.). Herein, is described the growth and structure of a new ambient pressure phase, $\varepsilon$, through a combination of optical and X-ray crystallography evaluated by computational crystal structure prediction algorithms. $\alpha$ Resorcinol has long been a model for mechanistic crystal growth studies from solution and the vapor because prisms extended along the polar axis grow much faster in one direction than in the opposite direction. Research has focused on identifying the absolute sense of the fast direction - the so-called 'resorcinol riddle' - with the aim of 
identifying how solvent controls crystal growth. Here, the growth velocity dissymmetry in the melt is analyzed for the $\beta$ phase. The $\varepsilon$ phase only grows from the melt, concomitant with the $\beta$ phase, as polycrystalline, radially growing spherulites. If the radii are polar, the sense of the polar axis is an essential feature of the form. Here, this determination is made for spherulites of $\beta$ resorcinol ( $\varepsilon$, point symmetry 222, does not have a polar axis) with additives that stereoselectively modify growth velocities. Both $\beta$ and $\varepsilon$ have the additional feature that individual radial lamellae may adopt helicoidal morphologies. We correlate the appearance of twisting in $\beta$ and $\varepsilon$ with the symmetry of twist-inducing additives.

\section{INTRODUCTION}

In a cautionary note in $2011,{ }^{1}$ we pointed out that recent claims by scientists to have created helical crystalline forms stereospecifically by the introduction of resolved additives, while surely intriguing, were pre-empted by Wallerant more than 100 years ago. Wallerant $\mathrm{t}^{2,3}$ was interested in mimicking in the laboratory the helicoidal forms of some fibrous quartz (chalcedony ${ }^{4}$ and quartzine ${ }^{5}$ ) crystals. $^{6}$ For instance, Wallerant showed that resorcinol crystals grow from the melt as spherulites ${ }^{7}$ formed of helicoidal fibrils that twisted to the right or to the left depending upon whether $(2 R, 3 R)-(+)$ or $(2 S, 3 S)-(-)$-tartaric acid is introduced into the growth medium. ${ }^{8}$ The mesoscale helical sense is controlled by the stereochemical configuration of the molecular additives. In repeating ${ }^{1}$ the experiments of Wallerant, we were faced with several new questions/challenges that are addressed herein including the following:

(1) Resorcinol crystals grow from the melt in the presence of tartaric acid additives as two distinct kinds of banded spherulites that can be easily differentiated optically. One was identified by powder X-ray diffraction as the long-known $\beta$ form of resorcinol. ${ }^{9,10,11}$ The other phase was unknown. We called it $\varepsilon$. $^{1}$ It was incumbent upon us to establish that we had indeed found a new ambient phase of resorcinol by solving its structure.

(2) Spherulites, by their very nature, grow unidirectionally, radially. When a polar crystallographic axis is the radial axis of a spherulite, we must know the absolute sense of that polar axis to understand the growth at the interface. Can we assign the absolute sense of a polar radial axis of a polycrystalline spherulite? The strategy we 


\section{GROWTH AND OPTICAL CRYSTALLOGRAPHY}

Growing Wallerant's mixed crystals was simple. A a sample of a few mg of mixed powders of resorcinol and tartaric acid was melted on a Kofler bench between a microscope slide and a cover glass and subsequently cooled. In the absence of tartaric acid, only the known forms, $\alpha$ and $\beta$, were observed. With 1-25 wt.\% $(2 R, 3 R)-(+)$ - or $(2 S, 3 S)$-(-)-tartaric acid, $\beta$ was still observed, but the unknown $\varepsilon$ form crystallized instead of the more stable $\alpha$ form. Crystallization of $\alpha$ was nevertheless obtained in the resorcinol/tartaric acid melt by seeding. Both $\beta$ and $\varepsilon$ simultaneously nucleated below $60{ }^{\circ} \mathrm{C}$ whereas at higher temperatures, nucleation was very slow. The three phases have different melting points (Table 1 ). The $T_{m}$ of nominally pure $\beta$ corresponds to the literature value of $109.6{ }^{\circ} \mathrm{C} .{ }^{19}$ In the presence of tartaric acid, the melting point decreases. Although accurate determination of $T_{m}$ was not possible because of fast $\alpha \rightarrow \beta$ and $\varepsilon \rightarrow \beta$ conversion and inhomogeneity in the distribution of tartaric acid, the differences in $T_{m}$ between different phases are consistent and can be used for the calculation of the free energy differences among polymorphs (Table 1). 
In the range of $40-75{ }^{\circ} \mathrm{C}, \varepsilon$ formed spherulites with a concentric optical rhythm (Figure $1 \mathrm{~b}, \mathrm{c}$ ) that indicates twisting of fibers along the growth direction. ${ }^{20,21,22,23,24,25} \mathrm{At}$ higher temperatures $\left(T>75^{\circ} \mathrm{C}\right)$ compact spherulites are replaced by open spherulitic networks with an irregular rhythm (Figure 1a). At lower temperatures $\left(T<30-40{ }^{\circ} \mathrm{C}\right)$ growth becomes irregular (Figure $1 d$ ). The twist period or pitch ( $\pi$ rotation of the fiber around the growth direction) increases with temperature (Figure 2) as is the case for most other materials. Curiously, for $\varepsilon$ resorcinol, two populations of pitches are usually observed at constant growth conditions (Figure 2). Tartaric acid is a prerequisite for twisting. In agreement with Wallerant's observations, we found that an admixture of $(2 S, 3 S)$-(-)-tartaric acid led to right-handed helicoidal crystals as determined by the method of sensing the screw, ${ }^{26,27}$ whereas $(2 R, 3 R)-(+)$-tartaric acid gave left-handed helicoids. (The mesoscale helicity was of opposite signs for $\beta$ ). ${ }^{1}$ As the concentration of tartaric acid increased, the pitch decreased, however, we were not able to quantify this dependence since at $<10$ wt.\% tartaric acid, the samples are inhomogeneous and the local concentration of tartaric acid cannot be reliably determined. At higher tartaric acid concentrations, a more or less homogeneous distribution of tartaric acid was achieved but the pitch had already reached saturation. The $\varepsilon$ structure slowly (down to $1 \mathrm{~mm} / \mathrm{year}$ ) transformed into $\beta$ starting from the edges of the melt. The transformation front propagated much faster with rates up to 1 $\mathrm{mm} / \mathrm{min}$ when the cover slip was removed. Moreover, nucleation of $\beta$ occurred over the whole area of the sample, leading to complete transformation within a few minutes.

Crystal optical properties of $\alpha^{19}$ and $\beta^{1}$ have previously been established. Here, we describe optical properties of the $\varepsilon$ form. As for $\beta, \varepsilon$ spherulites alternate between optically positive (slow direction radial) and negative (slow direction tangential) along the radii, indicating that the intermediate refractive index $N_{Y}$ is radial and that the minimum $\left(N_{X}\right)$ and maximum $\left(N_{Z}\right)$ refractive indices are exchanged as the radii twist, thereby forming concentric bands of optical contrast between crossed polarizers (Figure 1). Orientation of the optical indicatrix was obtained using X-ray diffraction texture analysis after matching experimental and simulated diffraction patterns (see 
below). The differences in refractive indices obtained from measured retardances are shown in Table 2.

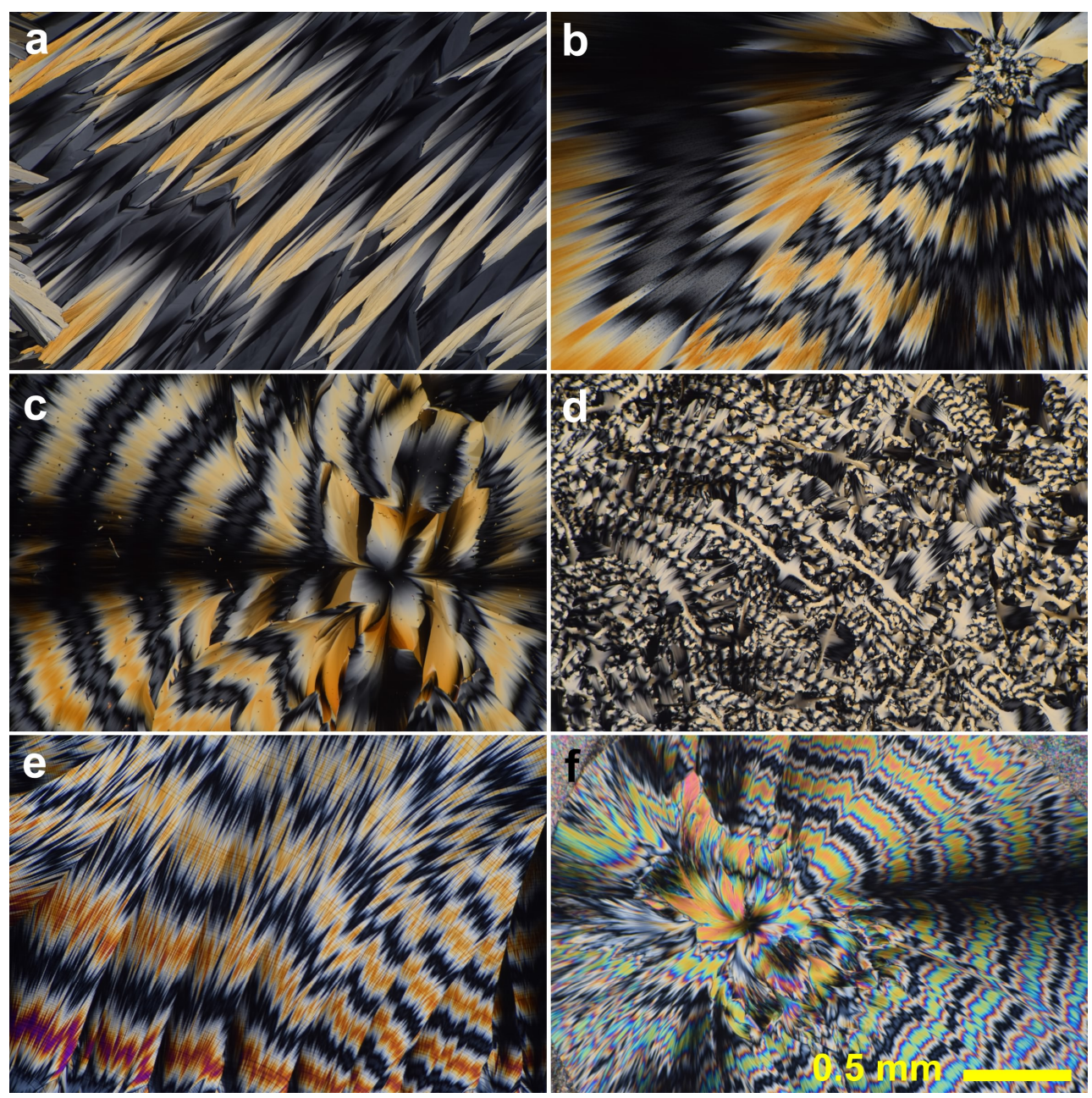

Figure 1. Polarized light optical micrographs of the $\varepsilon$ form. (a) Irregular banded spherulite formed at $80{ }^{\circ} \mathrm{C}$. (b) Banded spherulite formed at $75{ }^{\circ} \mathrm{C}$, showing two twist periods. (c) Banded spherulite formed at $51^{\circ} \mathrm{C}$. Irregular pattern with small areas of banded spherulites formed at $35{ }^{\circ} \mathrm{C}(\mathrm{d})$. Banded spherulites formed at room temperature in the presence of $20 \mathrm{wt} . \% 2$ methylresorcinol (e) and 5-methylresorcinol (f). 


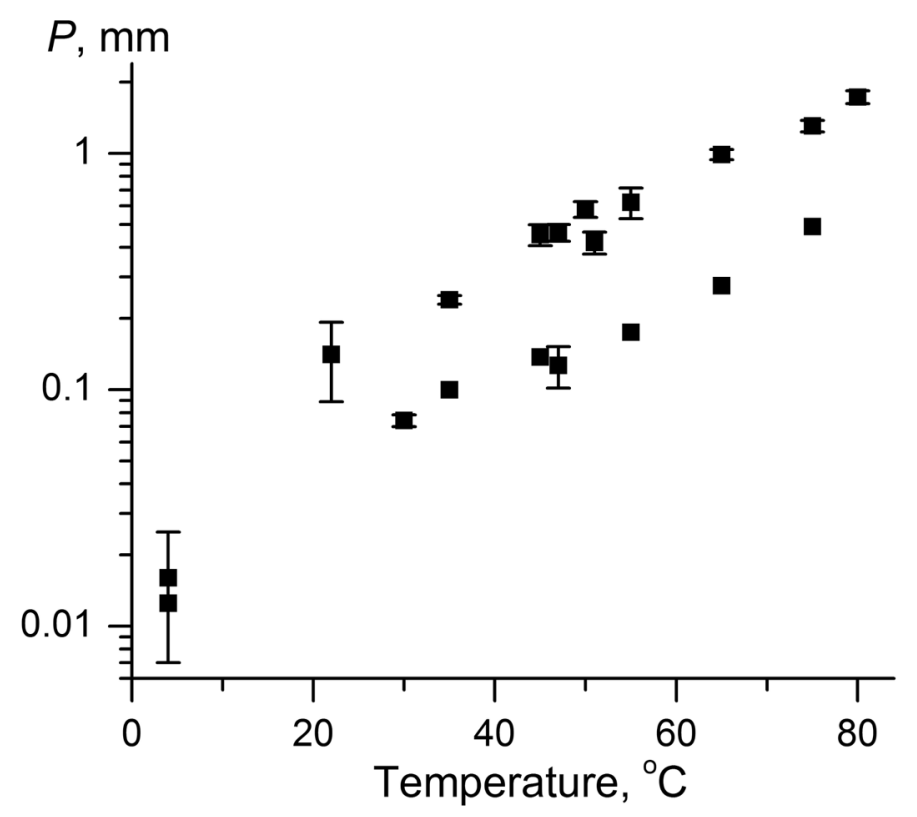

Figure 2. Twist period, $P$, of $\varepsilon$ as a function of growth temperature, $T$. Note two populations of twist periods for $T>22{ }^{\circ} \mathrm{C}$.

\section{$\varepsilon$-RESORCINOL}

Robertson, the first scientist to determine the X-ray structure of a pair of polymorphs<smiles>Oc1cccc(O)c1</smiles>

$\mathrm{R}_{\mathrm{a}}$<smiles>Oc1cccc(O)c1</smiles>

$\mathrm{R}_{\mathrm{b}}$<smiles>Oc1cccc(O)c1</smiles>

$\mathrm{R}_{\mathrm{c}}$

Scheme 1. Conformations of resorcinol molecule.

of an organic compound, resorcinol $\left(\mathrm{C}_{6} \mathrm{H}_{4}(\mathrm{OH})_{2}, 1,3\right.$-dihydroxybenzene), did not call out this singular achievement. ${ }^{28,29}$ Rather, he emphasized the difficulty of the structure analysis because resorcinol was the first molecular structure fully determined by X-ray crystallography that lacked site symmetry in the crystal, a difficult problem to solve by trial and error with random phasing models, especially in acentric crystals without phase restrictions on reflections. Here, we determine the 
structure of the first new crystalline phase of resorcinol persistent under ambient conditions since Robertson's pioneering work. ${ }^{30}$ The long quiescence in this subject is not for lack of opportunities; resorcinol is a major commodity chemical that is used in the manufacture of polymers, agrichemicals, and pharmaceuticals. ${ }^{31}$ Resorcinol phases $\alpha^{32}$ and $\beta^{33}$ are described by the polar space group $\operatorname{Pnaz}_{1}\left(Z^{\prime}=1\right)$. The polymorphism is associated with the conformational variations as shown Scheme 1. In the $\alpha$ polymorph, both hydroxyl groups are oriented downwards, away from the 2position, as in conformation $\mathrm{R}_{\mathrm{a}}$ (Scheme 1), while in the $\beta$ polymorph, the hydroxyl groups are oppositely oriented in the trans-like configuration of conformer $R_{b}$. Another low energy conformation, $R_{c}$, has only ever been observed in multicomponent crystal structures. ${ }^{34,35}$ Today, of course, structure determination of either of these crystals would take just hours. But, for polycrystalline samples, the determination of the structure of new polymorphs remains a challenge. ${ }^{36,37}$ Herein, we determine the structure of a third form of crystalline resorcinol, the $\varepsilon$ polymorph, by comparing computed structure predictions with available powder diffraction data. We had previously associated the third ambient pressure phase as $\gamma_{1}^{1}$ yet two high pressure phases have already claimed the $\gamma$ and $\delta$ identifiers. ${ }^{38,39,40,41,42,43}$ Therefore, we denote the new ambient phase $\varepsilon$.

Table 1. Melting points of resorcinol polymorphs.

\begin{tabular}{|c|c|c|c|c|c|}
\hline \multirow{2}{*}{$\begin{array}{l}\text { [tartaric } \\
\text { acid] wt.\% }\end{array}$} & \multicolumn{3}{|c|}{ Melting point, $T_{m},{ }^{\circ} \mathrm{C}$} & \multicolumn{2}{|c|}{$\Delta G, \mathrm{~kJ} / \mathrm{mol}^{\mathrm{a}}$ at $T_{m} \mathrm{c}$} \\
\hline & $\alpha$ & $\beta$ & $\varepsilon$ & $\beta-\alpha$ & $\beta-\varepsilon$ \\
\hline O & $106(1)$ & $110(1)$ & $\mathrm{n} / \mathrm{a}$ & 0.22 & $\mathrm{n} / \mathrm{a}$ \\
\hline 5.0 & $103(2)$ & $105(2)$ & 95(1) & 0.11 & 0.54 \\
\hline 15.8 & $101(2)$ & $103(2)$ & $96(2)$ & 0.11 & 0.44 \\
\hline
\end{tabular}

${ }^{\mathrm{a}} \Delta G=\left(T_{m(\beta)}-T_{m(\alpha / \gamma)}\right) \Delta H / T_{m(\beta)}$, where the heat of fusion $\Delta H=20.89 \mathrm{~kJ} / \mathrm{mol}^{38}$

Table 2. Crystal optical properties of resorcinol polymorphs.

$\begin{array}{llllllll}\text { Phase } & \text { OAP }^{\mathrm{a}} & N_{X} & N_{Z}-N_{X} & N_{Z}-N_{Y} & \text { Optic sign } & 2 V,{ }^{\circ} & \text { Ref. } \\ \alpha & (\text { oo1 }) & {[010]} & 0.049 & 0.22 & - & 46.23 & 19 \\ \beta & (\text { oo1 }) & {[100]} & 0.204^{\mathrm{b}} & 0.11^{\mathrm{b}} & + & 57(3) & 1 \\ \varepsilon & (\text { oo1 }) & {[100]} & 0.097 & 0.11 & + & 50(4) & \text { This work }\end{array}$

${ }^{\mathrm{a}}$ Optic axial plane; ${ }^{\mathrm{b}}$ Refined here as compared to ref. 1. 
Powder X-ray diffraction data of the $\varepsilon$ phase were collected in reflection mode using a microdiffractometer equipped with $2 \mathrm{D}$ detector (Figure 3 ) and matched with the crystal structure prediction results. Following the preparation of this manuscript, high-resolution powder data were recorded for the $\varepsilon$ phase on the ID22 beamline at the European Synchrotron Research Facility (Figure 4). The known polymorphs $\alpha, \beta$, and $\varepsilon$ all had distinct signatures in their micro-Raman spectra (Figure 5).

We turned to computation in order to arrive at the crystal structure whose simulated diffraction pattern matched experiment. Several crystal structure prediction

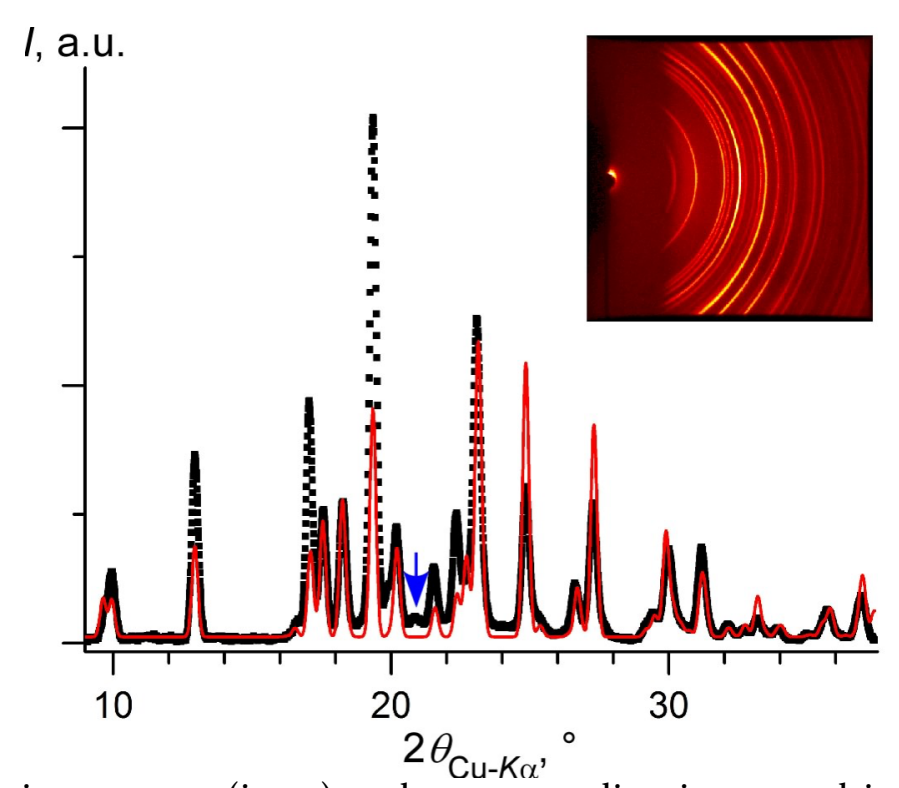

Figure 3. $2 \mathrm{D}$ diffraction pattern (inset) and corresponding integrated intensities of a powder sample of the $\varepsilon$ form (black dots). Sample contains $5 \mathrm{wt} . \%(2 S, 3 S)$-(-)-tartaric acid. Red line corresponds to the simulated diffraction pattern. The blue arrow points to the strongest maximum of the $\beta$ form.

attempts have been made, one of which applied a resorcinol-specific force field ${ }^{44}$ for energy minimization, although a number of changes were made. Firstly, we utilized RESP-A1A partial atomic charges calculated using the RESP ESP charge Derive (RED) Server web service, ${ }^{45}$ as these charges underpin the AMBER force field ${ }^{46}$ from which the bonded terms are taken. In an early attempt at predicting the crystal structure of resorcinol, we employed an MD strategy for the generation and evaluate of trial structures $^{47}$ (see Supporting Information). We found a number of new forms that were lower in energy than $\alpha$ and $\beta$. These were then optimized by density functional 
theory (DFT) calculations with Quantum ESPRESSO ${ }^{48}$ using the projector-augmented wave (PAW) method. ${ }^{49} \mathrm{~A}$ plane-wave kinetic energy cut-off of 80 Ry was used, and pseudopotentials were adapted from the atompaw library. ${ }^{50}$ Exchange and correlation effects were treated using the B86b-XDM functional, combining B86b exchange, ${ }^{51}$ PBE correlation ${ }^{52}$ and the exchange-hole dipole moment method (XDM) ${ }^{53,54}$ All of these structures were found to be higher in energy than both $\alpha$ and $\beta$. Hence, we refitted the non-bonded part in the form of Lennard-Jones 9-6 potentials (see supporting information for the details).

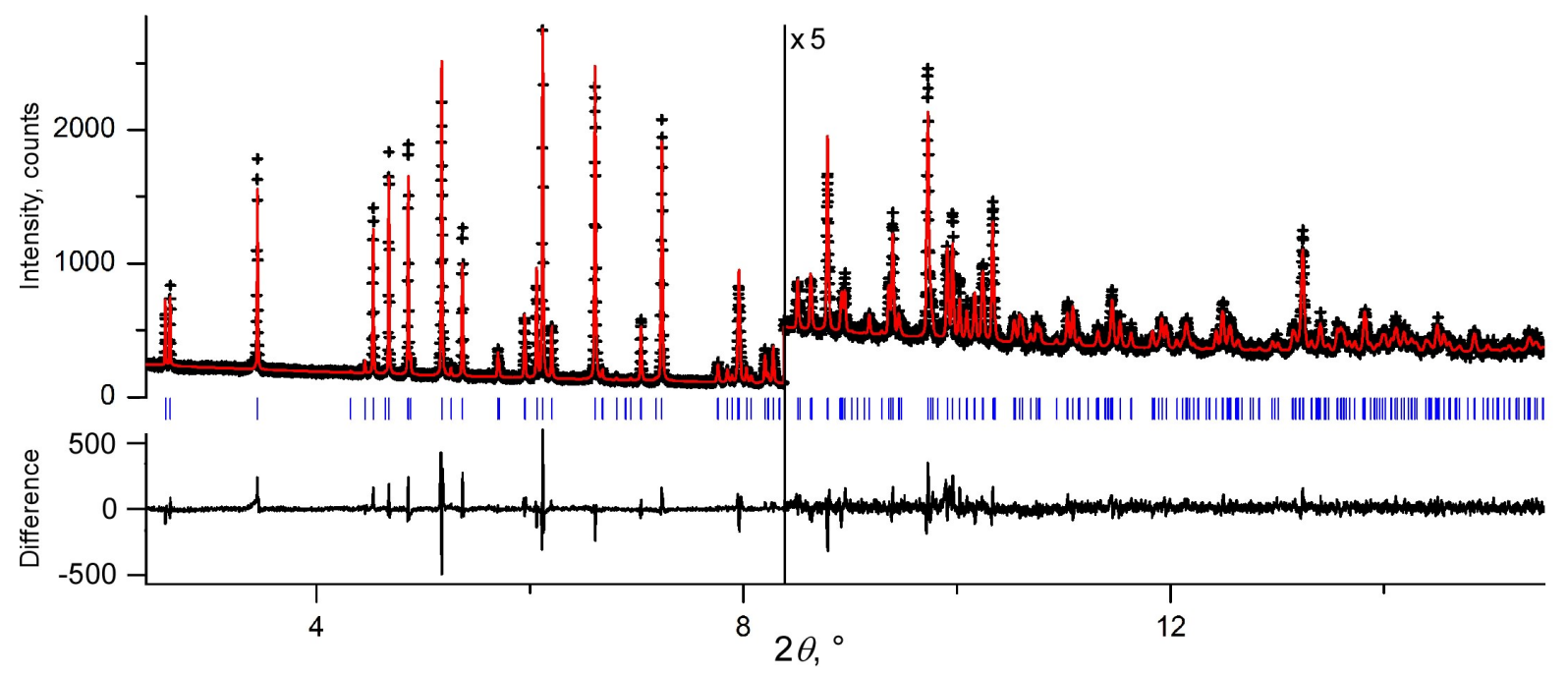

Figure 4. Rietveld refinement of high-resolution synchrotron powder diffraction for $\varepsilon$ resorcinol sample containing $5 \mathrm{wt} . \%(2 S, 3 S)$-(-)-tartaric acid. Observed (black crosses) and calculated (red line). $R_{\mathrm{wp}}=7.74 \%, \chi^{2}=0.838$. Data were collected at the ESRF at a wavelength of $0.41064 \AA$ and at a temperature of $200 \mathrm{~K}$. The lower trace shows the difference curve. 


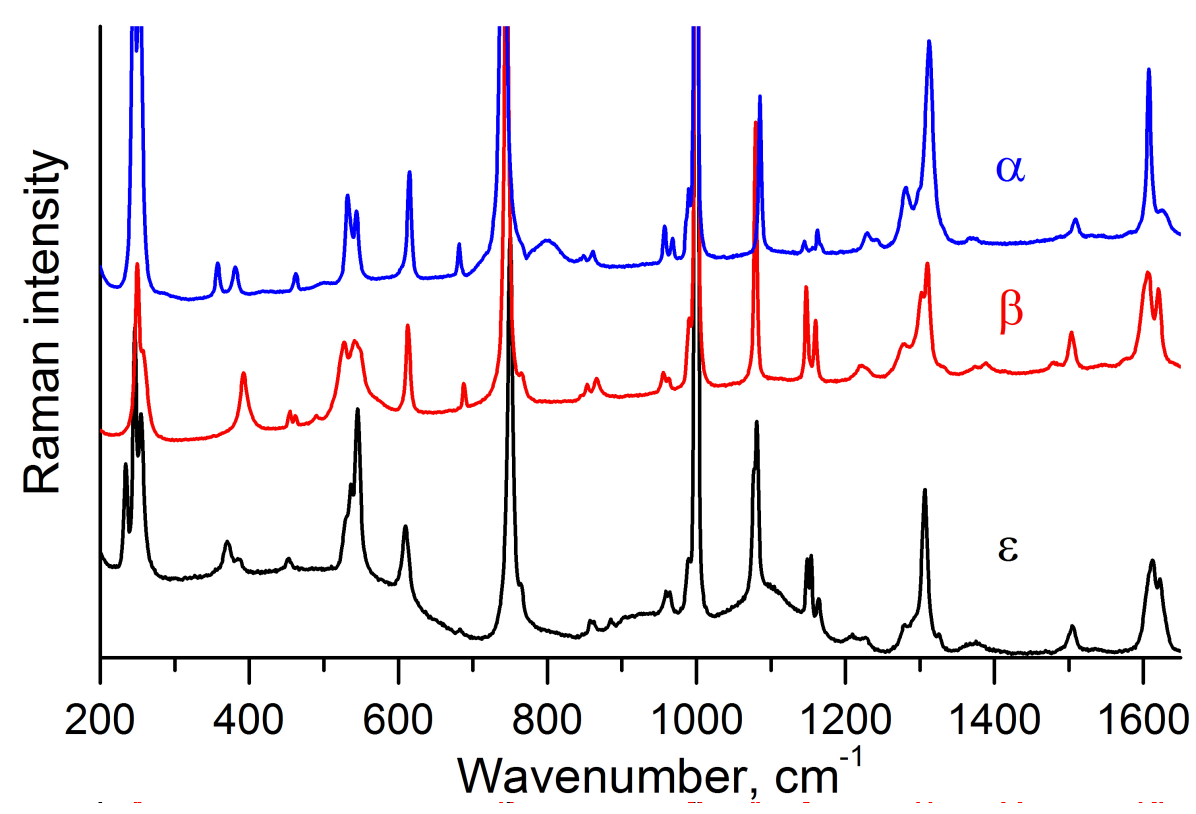

Figure 5. Raman spectra of resorcinol polymorphs.

Table 3. Comparison of structures of resorcinol polymorphs

$\begin{array}{cccccc}\text { Phase } & \alpha^{29} & \beta^{9} & \varepsilon^{\mathrm{a}} & \varepsilon^{\mathrm{b}} & P_{2_{1}} \\ \text { Conformation } & \mathrm{R}_{\mathrm{a}} & \mathrm{R}_{\mathrm{b}} & \mathrm{R}_{\mathrm{b}} & \mathrm{R}_{\mathrm{b}} & \mathrm{R}_{\mathrm{b}} \\ a(\AA) & 10.53(3) & 7.91(1) & 17.775 & 17.900 & 9.380 \\ b(\AA) & 9.53(3) & 12.57(2) & 10.715 & 10.568 & 5.466 \\ c(\AA) & 5.66(2) & 5.50(1) & 5.733 & 5.722 & 10.591 \\ \beta\left(^{\circ}\right) & 90 & 90 & 90 & 90 & 89.153 \\ V\left(\AA^{3}\right) & 568.0 & 546.9 & 1048.4 & 1082.4 & 543.0 \\ \text { Space group } & P n a 2_{1} & P n a 2_{1} & P 2_{12} 2_{1} 2_{1} & P 2_{1} 2_{12} 2_{1} & P 2_{1} \\ Z, Z & 4,1 & 4,1 & 8,2 & 8,2 & 4,2\end{array}$

${ }^{\mathrm{a}}$ Room temperature data collected with a microdiffractometer; ${ }^{\mathrm{b}}$ 200 K data collected at ESRF. Reported errors from least squares fitting of lattice parameters $\left(1-2 \times 10^{-4} \AA\right)$ are too small to be physically meaningful.

With these new potentials, we returned to crystal structure prediction. We performed a systematic crystal structure search for all three eclipsed conformers $R_{a}, R_{b}$, and $R_{c}$ (relative B86b-XDM (exchange-hole dipole moment) gas phase energies were found as 0.05, 0.0o, and $2.84 \mathrm{~kJ} / \mathrm{mol}$, respectively), based on evolutionary algorithms, as 
implemented in the USPEX code. ${ }^{55,56,57}$ Both GULP $^{58}$ using the refitted force field and DMACRYS $^{59}$ with a distributed multipole analysis (DMA) model ${ }^{60}$ were used to perform the structure relaxations within USPEX. The 25 lowest energy structures from each potential model were re-optimized using the B86b-XDM functional. For the most promising structures, we also performed phonon calculations at the B86b-XDM level using the finite-displacement approach as implemented in Phonopy. ${ }^{61}$ The vibrational entropy and enthalpies were obtained by summing over the phonon frequencies, in order to calculate the free energy.

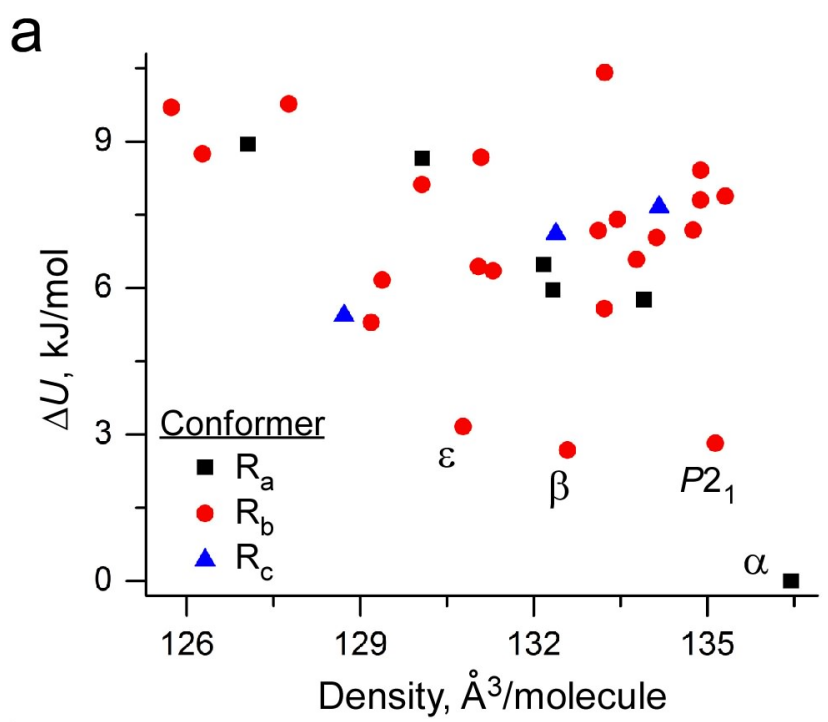

$\mathrm{b}$

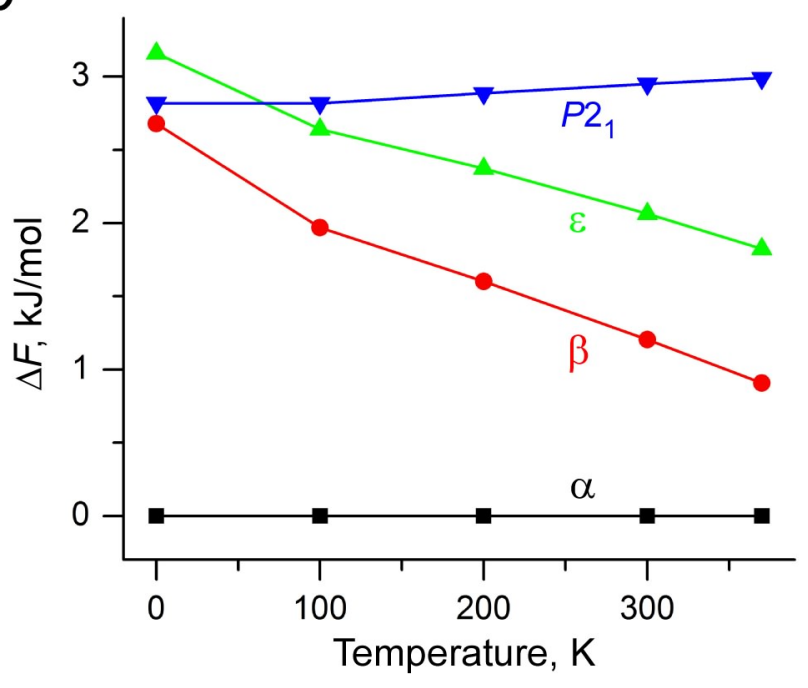

Figure 6. Energy comparison for various resorcinol polymorphs. (a) Lattice energy vs volume plot for all low energy structures found in the present study, as calculated at the B86b-XDM level of theory. (b) Helmholtz free energy differences vs temperature for selected polymorphs. 
As shown in the final energy plot (Figure 6), there are three unique crystal structures, with energy differences less than $5 \mathrm{~kJ} / \mathrm{mol}$ relative to the global energy minimum. The ground state is $\alpha$ and the $2^{\text {nd }}$ most stable structure is $\beta$. The $3^{\text {rd }}$ most stable structure has $P_{2_{1}}$ symmetry but it has not been observed. The simulated X-ray powder diffraction pattern of the $4^{\text {th }}$ most stable structure matches that of the new polymorph $\varepsilon$ (Figure 3 ). The orthorhombic lattice constants directly obtained from the simulation ( $a=17.634 \AA, b=10.361 \AA, c=5.738 \AA)$ were fitted using the FullProf suite ${ }^{62}$ (Table 3 ) to get the best correspondence with the experimental pattern. The crystal structure was further refined for the powder diffraction pattern collected at ESRF at $200 \mathrm{~K}$ using the FullProf suite. Geometries of both symmetry independent resorcinol molecules were fixed as rigid bodies. The best refinement (Figure 4) converged to $R_{\mathrm{p}}=$ $5.46 \%, R_{\mathrm{wp}}=7.74 \%, \chi^{2}=0.838$. The root mean-squared deviation (RMSD) between the models before and after refinement is only $0.145 \AA$ for 20 out of 20 molecules in

a

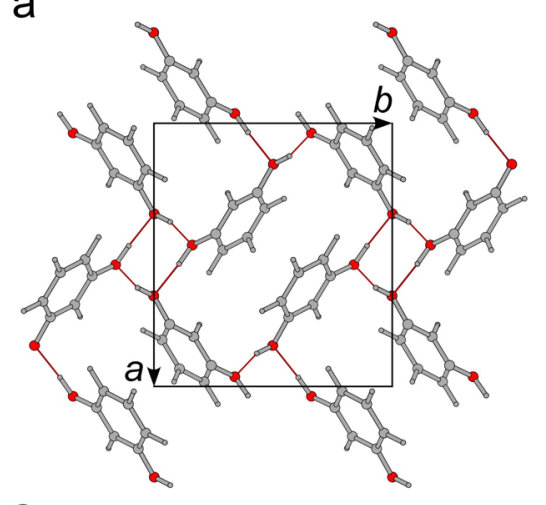

C

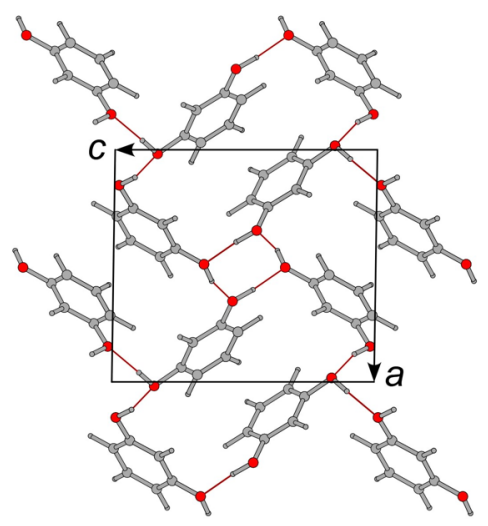

b

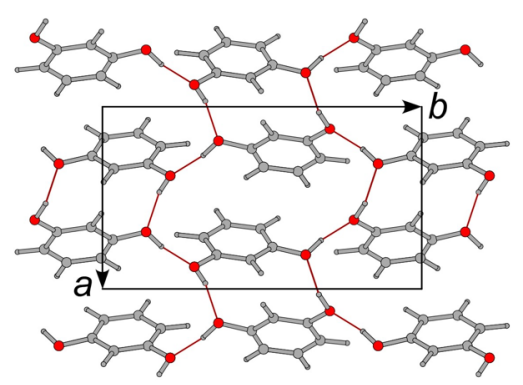

d

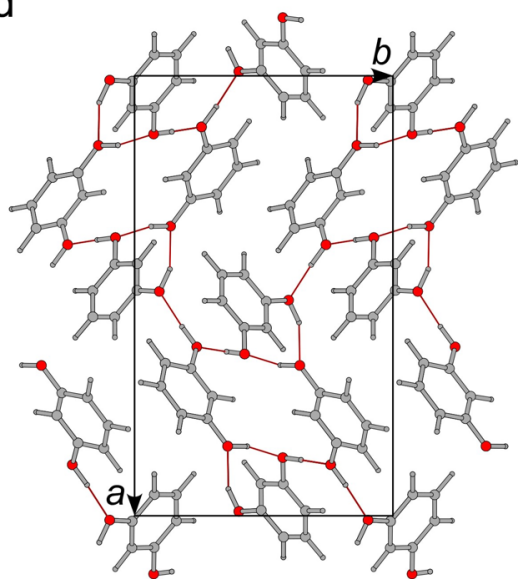

Figure 7. Resorcinol crystal structures (a) $\alpha$, (b) $\beta$, (c) $\varepsilon$, and (d) the $P_{2_{1}}$ phase. The views in each case are such that the molecules in any one structure project equal areas onto the plane of the page. 
the supercell.

The hydrogen bonding arrays of Robertson's $\alpha$ and $\beta$, as well as the new form $\varepsilon$, and the unobserved $P_{2}$ phase are compared in Figure 7. The resorcinol molecules form similar angles (ca. $63^{\circ}$ in $\alpha, 59^{\circ}$ in $\beta, 56^{\circ}$ in $\varepsilon$ ) with respect to the $a b$ plane and ca. $62^{\circ}$ with respect to the $a c$ plane for the $P_{2_{1}}$ phase. In the $\alpha$ structure, heterochiral, helical H-bonded arrays of four molecules run along the $2_{1}$ screw axes parallel to [oo1]; there is a pseudo tetragonal relationship. In the densest $\beta$ form, all rings are approximately parallel to the $b$ axis appearing with a herringbone arrangement in a projection running along the $c$ direction. The $\varepsilon$ form is enantiomorphous (point group $D_{2}$ ), whereas $\alpha$ and $\beta$ are polar $\left(C_{2 v}\right)$. In $\varepsilon$, hydroxyl groups make continuous chains comprised of both independent molecules that crudely trace square waves propagating along $b$. Meanwhile, only one of the independent molecules is situated such that both of its hydroxyls bridge these chains. The $P 2_{1}$ structure is similar to $\alpha$, however it consists of $\mathrm{R}_{\mathrm{b}}$ conformers as opposed to $\mathrm{R}_{\mathrm{a}} \cdot{ }^{63}$ The H-bonded chain still runs around the $2_{1}$ axis, now associated with the $b$ axis by convention, but the glide reflections are forfeited by the more dissymmetric conformers raising the value of $Z$ ' to 2.

The enthalpy of the $P 2_{1}$ structure is close to that of $\beta$, but is lower than that of $\varepsilon$. However, this monoclinic phase has not been observed. A recent computational study showed that the addition of vibrational free energy contributions affect rankings of polymorph stability. ${ }^{64}$ Therefore, we calculated the free energies for all four polymorphs at various temperatures. As shown in Figure $6 \mathrm{~b}$, the results near room temperature are in qualitative agreement with our experimental results. $P \mathbf{2}_{1}$ is decidedly higher in free energy at room temperature than any of the three phases that have been observed to date. The free energies in Figure $6 \mathrm{~b}$ are computed within the harmonic approximation. Not unexpectedly, anharmonic contributions to the free energy become important at higher temperatures. This issue is discussed in greater detail in the supporting information.

Despite the high free energy of the $P \mathbf{2}_{1}$ polymorph, we sought to test its stability by subjecting this structure to molecular dynamics in the isothermal-isobaric ensemble at $370 \mathrm{~K}$ and $1 \mathrm{~atm}$ pressure. Over the course of the run, we observed no significant 
changes in the averages of the cell parameters that would signify a structural transition.

In parallel to this study, crystal structure prediction calculations were also performed using a quasi-random sampling approach to global lattice energy exploration, as implemented in the GLEE code ${ }^{65}$ including all three conformers in $Z^{\prime}=$ 1 and all conformational combinations in $Z^{\prime}=\mathbf{2}$. These structures were lattice energy minimised using a transferable exp-6 atom-atom pontential and atomic multipoles, using DMACRYS and CrystalOptimizer ${ }^{66}$ to allow molecular flexibility during optimization. See workflow (Figure $\mathrm{S}_{1}$ ). This study also found the $\alpha, \beta, \varepsilon$ and $P_{2_{1}}$ forms with very similar energy ranking to the B86b-XDM results, in addition to a number of other potential low energy polymorphs involving all three molecular conformers (see Supporting Information).

\section{THE RESORCINOL RIDDLE}

Background. A great deal of attention has been directed at a question that goes by the name of 'the resorcinol riddle'. ${ }^{17}$ In 1949, Wells ${ }^{67}$ noted that the common phase of solution grown resorcinol, $\alpha$, grows much faster in one direction along its polar $c$ axis than in the opposite direction. He speculated that the hydroxyl rich end was probably retarded in aqueous solutions because of strong hydrogen bonds with water that must disassociate for the crystals to continue to grow. Consequently, the aryl "hind quarters" on the opposite side of the crystal would more readily add new solute molecules. This prediction lurked in the literature. Two scientists tried to make the absolute assignment of the fast growing direction of the polar axis in respective dissertations from Zürich ${ }^{68}$ and Rehovot. ${ }^{69}$ The work accomplished therein was characterized in accessible publications by, respectively, Milisajevic with Davey and Bourne, ${ }^{70}$ and by Wireko with Leiserowitz, Lahav among others. ${ }^{17}$ Chemical assignments were used to determine the sense of the polar axis. Oriented nuclei on silica surfaces grow slowly. Assuming resorcinol is bound to silica through the hydroxyl rich end, the fast growing surface was then hydroxyl rich. Habit and growth rate changes in the presence of tailor-made additives, in conjunction with the anomalous dispersion of X-rays to directly assign the sense of the polar axis, were in agreement with one another and likewise supported the notion that the hydroxyl rich 
end was fast growing, in contrast to Wells. While the ends of the polar axis are quickly distinguished as hydrophobic $(+c)$ and hydrophilic $(-c)$, the growth actually occurs on $\{011\}$ and $\left\{\mathrm{o}_{1} \overline{1}\right\}$ faces. The $-\mathrm{OH}$ groups actually emerge at the slow growing end, because this end more strongly associates with hydrogen bonds accepting solvent molecules. Wells got the wrong answer for the right reason. These judgments were later supported by molecular dynamics calculations ${ }^{71}$ of water binding to the resorcinol surfaces as well as density functional theory. ${ }^{72}$ Taken together, this body of work spoke directly to important questions regarding solvent control of crystal growth originally framed by Wells. Moreover, preferential dissolution at the fast growing end was consistent with the protection of the slow end by strongly bound solvent molecules.

Resorcinol sublimes easily. In 2005, Srinivasan and Sherwood reported that resorcinol likewise grows rapidly in the [oo $\overline{1}]$ direction from the vapor, suggesting that the growth dichotomy was intrinsic to resorcinol, and that there was no need to invoke solvent control as an explanation, as solvent and water vapor were rigorously excluded in their experiments. ${ }^{73}$ They suggested the self-poisoning of the slow growing faces by resorcinol in a minor orientation could account for comparable observations in solution and in the vapor. The problem was reviewed the next year by Lahav and Leiserowitz ${ }^{74}$ followed by force field calculations with Weissbuch ${ }^{75}$ that supported the self-poisoning proposition consistent with the concept of stereocontrolled additive inhibition. In 2011, Srinivasan and Sherwood emphasized the differences in microtopography on the faces of the crystals developed on opposing ends, illustrating intrinsic growth differences that are required by symmetry. ${ }^{76}$

In 2007, more extensive MD simulations revealed that the slow growing \{o11\} faces were worse off than merely self-poisoned, they were ill-constructed with jumbled interfaces not suited to rapid growth. ${ }^{77}$ Even more recent simulations from just last year showed that in fact, the fast growing faces also accumulate molecules in a jumble, but these quickly rearrange so as to increase the length of the crystal at the $+c$ end. They likened this process to the two-step nucleation mechanism ${ }^{78}$ which has transformed our understanding of crystal growth. ${ }^{79}$ In the very latest simulation, the same authors open the door to experiments in the melt. They show that the $\alpha$ phase in 
equilibrium with melt slabs capping the polar axis, do indeed grow with asymmetric rates as expected at temperatures below $60{ }^{\circ} \mathrm{C}{ }^{80}$

Is this the last words on the resorcinol riddle? We are afraid not. We owe a debt to the resorcinol riddle because Chatchawalsaisin et al., to provide a solution with molecular dynamics simulations, developed an optimized resorcinol force field that was helpful in our determination of the structure of the $\varepsilon$ phase. ${ }^{44}$ Here, we repay this debt in two ways: 1. By extending the resorcinol riddle to experiments from the melt; previously asymmetric growth was only evaluated by experiment in the vapor and in solution, and 2. By extending the resorcinol riddle to the other polar phase, $\beta$.

The $\beta$ resorcinol riddle: Tailor made additives in the melt and the absolute sense of growth in polar spherulites. In spherulites, there is only one fast growing direction, the radius outward, no matter what crystallographic direction or set of symmetry related directions that is. The spherulites in Figure 1 of the $\beta$ and $\varepsilon$ forms both have one crystallographic radius, and one fast growing direction or symmetry related directions.

$\alpha$ and $\beta$ resorcinol share the same polar space group, Pnaz ${ }_{1}$. Thus, we might ask whether $\beta$ resorcinol single crystals in the melt also grow more rapidly in one direction rather than another. Unfortunately, there is nothing in the literature about the morphology or growth kinetics of the $\beta$ phase which is stable only at elevated temperatures. It is difficult to work with in solution as it quickly transforms to $\alpha$ at room temperature. However, in the melt, it is persistent. Single crystals of $\beta$, rather than spherulties, can be obtained at small supercoolings. We had earlier established by optical crystallography and powder X-ray diffraction that the polar axis <0o1> is the radial direction in the spherulites. ${ }^{1}$ But we do not know whether the fast direction is [oo1] or [oo $\overline{1}]$. We can address this question by using tailor made additives following the logic of Leiserowitz, Lahav and coworkers, who have previously shown that pyrogallol (Scheme 2) stereoselectively inhibits fast growing oxygen-rich $\{01 \overline{1}\}$ faces of $\alpha$ resorcinol whereas pholoroglucinol, orcinol (Scheme 2 ), and $\alpha$-resorcylic acid inhibit slow growing hydrogen-rich $\{011\}$ faces (Figure 8a). ${ }^{16,17,74,75}$ 


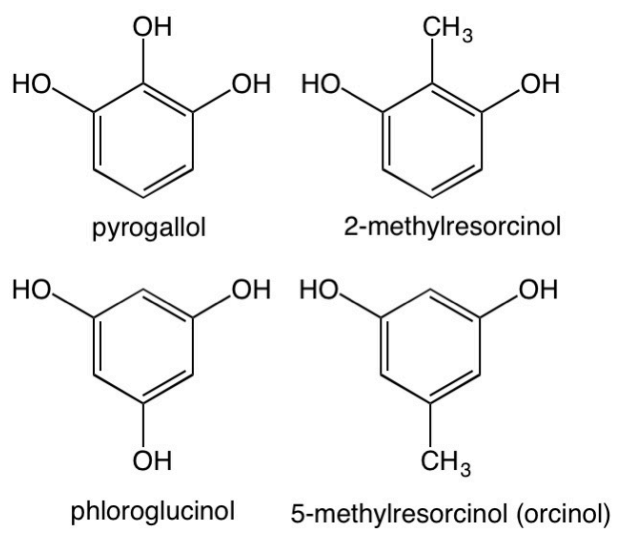

Scheme 2. Tailor made additives used to establish polar direction of $\beta$ resorcinol.

We selected a similar set of additives with small differences. The four compounds in Scheme 2 come in isomeric pairs, pyrogallol and phloroglucinol, as well as 2methylresorcinol (not in the set used previously) and 5-methylresorcinol (orcinol) respectively. Pyrogallol and 2-methylresorcinol should slow the hydroxyl rich end, as the benzene ring is unencumbered by docking the aryl ring side first, whereas pyrogallol and 5-methyresorcinol will bind to the slow growing end with obstructing hydroxyl or methyl groups exposed at the interface. The rate of growth of $\beta$ spherulites was tested for these two pairs of compounds, at several different concentrations in the melt. However, we dismissed the use of the trihydroxybenzene isomers because phloroglucinol had considerably higher melting than resorcinol (219 vs. $110{ }^{\circ} \mathrm{C}$ ) obviating the preparation of homogeneous melts of known composition. Thus, here we focus on the methyl derivatives of resorcinol, whose melting points are close to that of resorcinol, 2-methylresorcinol $\left(114-120^{\circ} \mathrm{C}\right)$, and 5-methylresorcinol $\left(106-112{ }^{\circ} \mathrm{C}\right)$.

Figure 9 shows the effect of additive concentration on the growth rate of single crystals and spherulites. Data are plotted only for the faster <oor $>$ direction since in single crystals the slower <oor $>$ end is essentially immobile; in spherulites only the growth of the direction can be observed. Not surprisingly, the additives slow down crystallization presumably affecting the mass transport in the crystallization medium. 
For single crystals, growth at small supercoolings is mainly controlled by the interface kinetics. Since 2-methylresorcinol inhibits crystallization much more strongly than 5-methylresorcinol, there should be specific interactions between the faster <oo1> direction and the 2-methylresorcinol molecules. Assuming that 2methylresorcinol can more easily adsorb to and inhibit \{o11 growth faces than $\{01 \overline{1}\}$ (Figure $8 \mathrm{~b}$ ) one can surmise that the faster growth occurs along $+c$ direction. Thus, we can assign the radial growth direction of spherulites as $+c$.

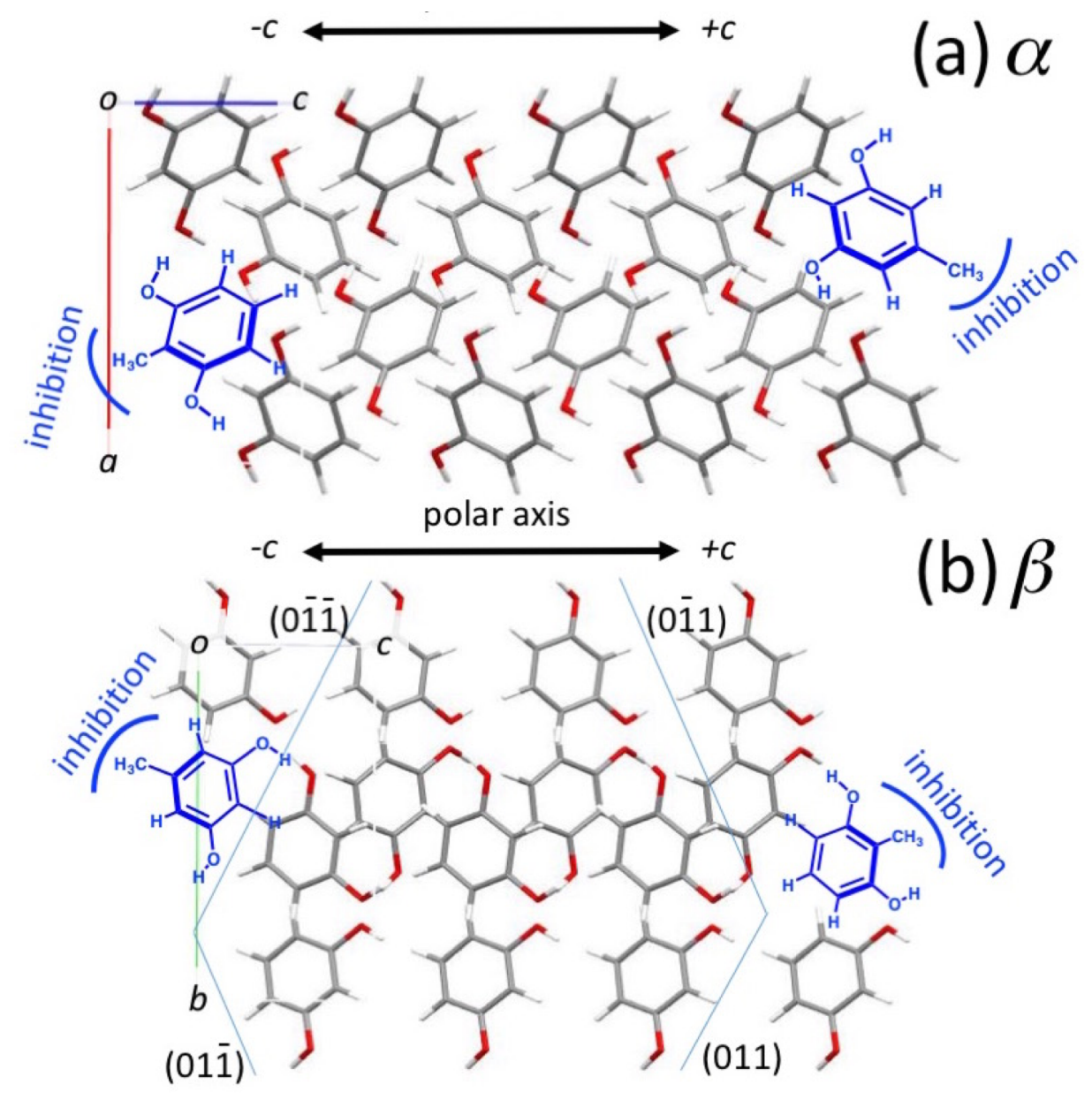

Figure 8. Projections of crystal structures of $\alpha$ (a) and $\beta$ (b) resorcinol normal to the polar axes on (010) and (100) planes, respectively. For $\alpha$ resorcinol, the 5methylresorcinol and 2-methylresorcinol molecules can bind to the $+c$ and $-c$ directions, respectively, and subsequently block them. For $\beta$ resorcinol, 5methylresorcinol and 2-methylresorcinol molecules can bind to the $-c$ and $+c$, respectively.

In the case of spherulites forming at room temperature, the growth rate decrease is comparable for both additives. This observation can be attributed to the fact that at high supercooling growth rate is mostly controlled by diffusion/viscosity and not by 

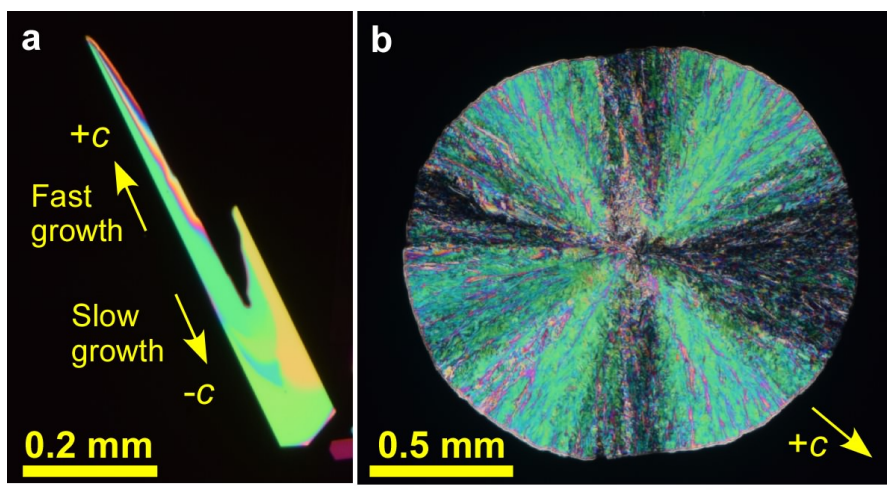

c

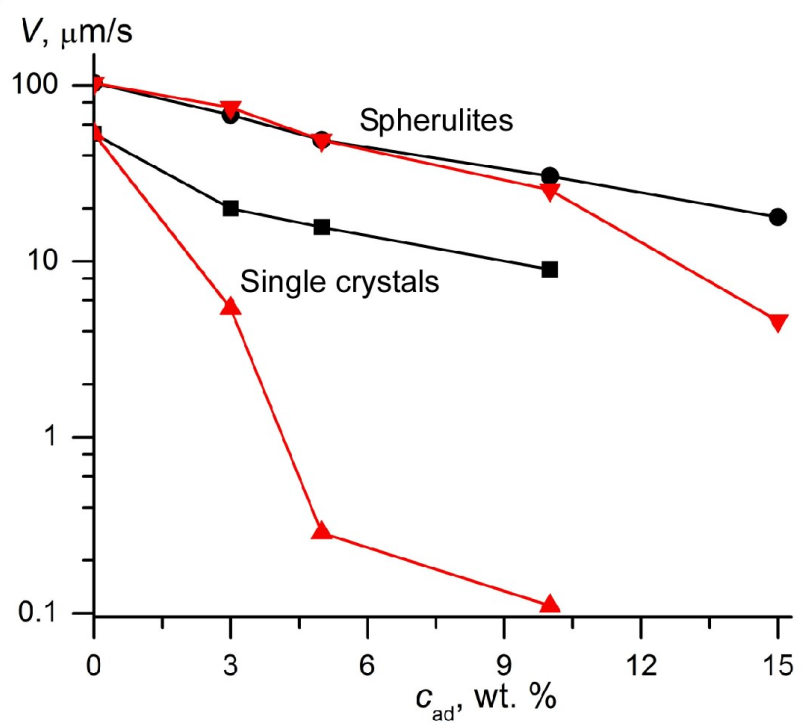

Figure 9. $\beta$ resorcinol single crystals (a) and spherulites (b) growing from the melt close to the melting point and at the room temperature, respectively. Admixture of 5 -methylresorcinol $10 \mathrm{wt} . \%$. c. Effect of 2-methylresorcinol (red symbol and lines) and 5-methylresorcinol (black symbol and lines) admixture on the growth rate of $\beta$ resorcinol in the faster $+c$ direction in single crystals formed at supercooling of $0.5{ }^{\circ} \mathrm{C}$ (up triangles and squares) and spherulites formed at room temperature (down triangles and circles).

A $\varepsilon$ resorcinol riddle. Is there a riddle of $\varepsilon$ resorcinol? If by riddle we mean absolute direction of growth, the answer is "No". $\varepsilon$ Resorcinol has point symmetry 222 $(D 2)$ and is devoid of a polar axis. $\varepsilon$-Spherulites do not have an absolute sense of radial growth. But, one aspect of this new phase that is not fully understood is that the $\varepsilon$ phase always forms twisted crystalline fibrils or lamellae, a feature that sometimes applies to the $\beta$ phase. Figure 1 poses a different riddle: what is the etiology of the 
twisting, the feature of resorcinol growth from the melt that attracted us to resorcinol growth in the first place. ${ }^{1}$ Why and when are the crystals of the $\beta$ and $\varepsilon$ twisted? This is a much older, ${ }^{8}$ resorcinol riddle. It is also a riddle, that transcends resorcinol, and applies to many materials scattered throughout the kingdom of crystals that are likewise twisted. ${ }^{21}$

Although the twisting mechanism remains an open question at present, we can make several comments about the twisting mechanism in $\beta$ and $\varepsilon$. The $\beta$ phase grows as needles along $c$. Because of the crystal symmetry, the crystal tip is bisected by two reflection planes. The $\beta$ phase cannot twist in the absence of a chiral additive. Indeed, $(2 R, 3 R)-(+)$ and $(2 S, 3 S)-(-)$-tartaric acid twist the $\beta$ phase in opposite directions, as compared with $\varepsilon$. Racemic acid produces untwisted fibrils. The $\varepsilon$ phase forms enantiomorphous crystals in the space group $P \mathbf{2}_{1} \mathbf{2}_{1} \mathbf{2}_{1}$. Crystal twisting generally requires an additive, however because the crystals are chiral, the additive need not be. Indeed, the achiral additives 2- and 5-methylresorcinol produce smooth spherulites of $\beta$ with straight fibrils (Figure $9 \mathrm{~b}$ ), while they produce banded spherulites of $\varepsilon$ with twisted fibrils (Figure 1e,f). Thus, the twisting can be predicted on the basis of the symmetries of host and guest which strongly supports mixed crystal formation as the origin of twisting. All evidence points to an interaction between the two agents wholly consistent with the Neumann-Curie Principle of Symmetry. ${ }^{18}$

Why tartaric acid favors the formation of a new phase remains a mystery. As tartaric acid has a much higher melting point than resorcinol, it may be that microcrystals precipitate from the melt and epitaxially nucleate the new phase.

\section{Experimental Section}

A few mg of resorcinol(Sigma-Aldrich, 99\%) mixed with o-25 wt.\% $(2 R, 3 R)-(+)$ - or $(2 S, 3 S)-(-)$-tartaric acid were placed between a microscope slide and a glass cover slip and melted on a Kofler bench at ca. $180-190{ }^{\circ} \mathrm{C}$. The temperature was higher than the resorcinol melting point $\left(T_{m}=110{ }^{\circ} \mathrm{C}\right)$ in order to melt the tartaric acid $\left(T_{m}=171-174\right.$ $\left.{ }^{\circ} \mathrm{C}\right)$ as well. Then the samples were cooled and crystallized either at room temperature or on a Kofler bench at $30-90{ }^{\circ} \mathrm{C}$ or in a refrigerator at $4{ }^{\circ} \mathrm{C}$. Some samples were remelted and subsequently crystallized on a hot stage (Model FP9o, Mettler-Toledo). Polarized light micrographs were made with an Olympus BX $_{50}$ microscope equipped 


\section{ASSOCIATED CONTENT}

\section{Supporting Information}

The supporting information is available free of charge on the ACS publications website at DOI: XXXXX.

Force field generation with partial charges and Lennard-Jones parameters, lattice parameters, crystallographic information files, crystal structure prediction using GLEE, rigid molecule workflow, structure generation settings, DMACRYS parameters, resorcinol conformers, clustering with COMPACK, internal degrees of freedom, additional DMACRYS parameters, final CSP polymorph landscape, Curtin resorcinol structures, Southampton resorcinol structures. 


\section{AUTHOR INFORMATION}

\section{Corresponding Authors}

*a.rohl@curtin.edu.au, mark.tuckerman@nyu.edu, bart.kahr@nyu.edu Notes

The authors declare no competing financial interest.

\section{ACKNOWLEDGEMENTS}

Dedicated to Les Leiserowitz and Meir Lahav for obvious reasons and many others besides. This work was primarily supported by the New York University Materials Research Science and Engineering Center (MRSEC) program of the National Science Foundation under award number DMR-1420073. Only ARO was supported by DARPA (No. $\mathrm{W}_{31} \mathrm{P}_{4} \mathrm{Q}_{1210008}$ and $\mathrm{W}_{31} \mathrm{P}_{4} \mathrm{Q}_{1310005}$ ). Funding support was also provided by the Australian Research Council (grants FT130100463 and DP140101776). This work was supported by computational resources provided by the Australian Government through the Pawsey Centre under the National Computational Merit Allocation Scheme. GMD and PJB were supported by the EPSRC via grant EP/Jo111oX/1 and acknowledge the use of the IRIDIS High Performance Computing Facility, and associated support services at the University of Southampton, in the completion of this work. Data for the crystal structure prediction are accessible through the University of Southampton Institutional Research Repository, DOI: 10.5258/SOTON/386575. We thank Professor Michael D. Ward for the use of his atomic force microscopes and X. Cui for atomic force microscopy. The authors acknowledge Dr. Chunhua Hu (NYU Department of Chemistry X-ray Diffraction Facility) and the NSF Chemistry Research Instrumentation and Facilities Program (CHE-0840277) for the powder microdiffractometer. The high resolution powder diffraction experiments were performed on beamline ID22 at the European Synchrotron Radiation Facility (ESRF), Grenoble, France. We are grateful to Dr. Carlotta Giacobbe for providing assistance in using the beamline. We also thank Dr. Eva Weber and Maria Koifman for their assistance in data collection. 
Keywords: resorcinol $\bullet$ polymorphism $\bullet$ crystal structure prediction $・$ X-ray diffraction

\section{References}

1. Kahr, B.; Shtukenberg, A.; Gunn, E.; Carter, D. J.; Rohl, A. L. Cryst. Growth Des. 2011, 11, 2070.

2. Wallerant, F. C. R. Acad. Sci. (Paris) 1906, 143, 555.

3. Wallerant, F. C. R. Acad. Sci. (Paris) 1906, 143, 1169.

4. Michel-Levy, A.; Munier-Chalmas, C. P. E. Bull.Soc. Fr. Mineral. 1892, 15, 159.

5. Wallerant, F. Bull. Soc. franc. Min. 1897, 20, 52.

6. Michel-Levy, A.; Munier-Chalmas, C. P. E. Bull. Soc. Fr. Mineral. 1892, 15, 159.

7. Shtukenberg, A.; Punin, Yu.-O.; Gunn, E.; Kahr, B. Chem. Rev. 2012, 112, 1805.

8. Wallerant, F. Bull. Soc. Fr. Mineral. 1907, 30, 43.

9. Ubbelohde, A. R.; Robertson, J. M.; Nature, 1937, 239.

10. Robertson, J. M.; Ubbelohde, A. R. Proc. R. Soc. London, Ser. A: Math. Phys. Sci. 1938, 167, 122.

11. Robertson, J. M.; Ubbelohde, A. R. Proc. R. Soc. London, Ser. A: Math. Phys. Sci. 1938, $167,136$.

12. Addadi, L.; Berkowitch-Yellin, Z.; Weissbuch, I.; van Mil,J.; Shimon, L. J. W.; Lahav, M.; Leiserowitz, L. Angew. Chem., Int. Ed. 1985, 24, 466.

13. Addadi, L.; Berkovitch-Yellin, Z.; Weissbuch, I.; Lahav, M.; Leiserowitz, L. In Topics in Stereochemistry; Eliel, E. L., Willen, S. H., Allinger, N. L., Eds.; John Wiley \& Sons Inc.: New York, 1986; Vol. 16, p 1.

14. Weissbuch, I.; Addadi, L.; Lahav, M.; Leiserowitz, L. Science 1991, 253, 637.

15. Weissbuch, I.; Popovitz-Biro, R.; Lahav, M.; Leiserowitz, L. Acta Crystallogr. Lead Article 1994, B51, 115 .

16. Shimon, L.J.W.; Wireko, F. C.; Wolf, J.; Wiessbuch, I.; Addadi, L;. BerkovitchYellin, Z. Lahav, M.; Leiserowitz, L. Mol. Cryst. Liq. Cryst. 1986, 137, 67.

17. Wireko, F. C.; Shimon, L. J. W.; Frolow, F.; Berkovitch-Yellin, Z.; Lahav, M.; Leiserowitz, L. J. Phys. Chem. 1987, 91, 472.

18. Shtukenberg, A. G.; Punin, Yu. O. Optically Anomalous Crystals, (Kahr, B. ed.) Springer, Dordrecht, 2007; Chapter 3.

19. Winchell, A. N. The Optical Properties of Organic Compounds; McCrone Research Institute: Chicago, 1987.

20. Bernauer, F. “Gedrillte” Krystalle, Gebrüder Borntraeger, Berlin, 1929.

21. Shtukenberg, A.; Punin, Yu. O.; Gujral, A.; Kahr, B. Angew. Chem. Int. Ed. 2014, 53, 672. 
22. Shtukenberg, A.; Gunn, E.; Gazzano, M.; Freudenthal, J.; Camp, E.; Sours, R.; Rosseeva, E.; Kahr, B. ChemPhysChem 2011, 12, 1558.

23. Shtukenberg, A. G.; Cui, X.; Freudenthal, J.; Gunn, E.; Camp, E.; Kahr, B. J. Am. Chem. Soc. 2012, 134, 6354.

24. Cui, X.; Rohl, A. L.; Shtukenberg, A.; Kahr, B. J. Am. Chem. Soc. 2013, 135, 3395.

25. Cui, X.; Shtukenberg, A.; Freudenthal, J.; Nichols, S. M.; Kahr, B. J. Am. Chem. Soc. 2014, 136, 5481 .

26. Shtukenberg, A. G.; Freudenthal, J.; Kahr, B. J. Am. Chem. Soc. 2010, 132, 9341.

27. Keith, H. D.; Padden, F. J. J. Polym. Sci. 1959, 39, 123.

28. Robertson, J. M. Nature 1935, 136, 755.

29. Robertson, J. M. Proc. R. Soc. London, Ser. A: Math. Phys. Sci. 1936, 157, 79.

30. Druzbicki, K.; Mikuli, E.; Palka, N.; Zalweski, S.; Ossowska-Chruściel, M. D. J. Phys. Chem. B 2015, 119, 1681.

31. Durairaj, R. B. Resorcinol: Chemistry, Technology, and Applications, SpringerVerlag, Berlin, 2005.

32. Bacon, G. E.; Jude, R. J. Z. Kristallogr. 1973, 138, 19.

33. Bacon, G. E.; Curry, N. A. Proc. R. Soc. London Sect. A 1956, 235, 552.

34. Papaefstathiou, G. S.; MacGillivray, L. R. Org. Lett., 2001, 3, 3835.

35. Bucar, D.-K.; Sen, A.; Mariappan, S.V.S.; MacGillivray, L.R. Chem.Commun. 2o12, 48, 1790.

36. Bacon, G. E.; Lisher, E. J. Acta Crystallogr. Sect. B. 1980, B36, 1908.

37. Dinnebier, R. E.; Billinge, S. J. L. eds. Powder Diffraction: Theory and Practice, Royal Society of Chemistry, London, 2008.

38. Ebisuzaki, Y.; Askari, L. H.; Bryan, A. M.; Nicol, M. F. J. Chem. Phys. 1987, 87, 6659.

39. Kichanov, S. E.; Kozlenko, D. P.; Biliski, P.; Wąsicki, J.; Nawrocik, W.; Medek, A.; Hancock, B. C.; Lukin, E. V.; Lathe, C.; Dubrovinsky, L. S.; Savenko, B. N. J. Mol. Struct. 2011, 1006, 337.

40. Deb, S. K.; Rekha, M. A.; Roy, A. P.; Vijayakumar, V.; Meenakshi, S.; Gudwal, B. K. Phys. Rev. B 1993, 47, 11491.

41. Rao, R.; Sakuntala, T.; Godwal, B. K. Phys. Rev. B 2002, 65, 054108.

42. Rao, R.; Sakuntala, T.; Arora, A. K.; Deb, S. K. J. Chem. Phys. 2004, 121, 7320.

43. Ossowska-Chruściel, M. D.; Juszyńska-Gałązka, E.; Zając, W.; Rudzki, A.; Chruściel, J. J. Mol. Struct. 2015, 1082, 103-113.

44. Chatchawalsaisin, J.; Kendrick, J.; Tuble, S. C.; Anwar, J. CrystEngComm 2oo8, 10, 437 .

45. Vanquelef, E.; Simon, S.; Marquant, G.; Garcia, E.; Klimerak, G.; Delepine, J. C.; Cieplak, P.; Dupradeau, F.-Y. R.E.D. Server: a web service for deriving RESP and 
ESP charges and building force field libraries for new molecules and molecular fragment, Nucl. Acids Res. (Web server issue) 2011, W511-W517,http://q4mdforcefieldtools.org/REDS/

46. Case, D. A.; Cheatham III, T. E.; Darden, T.; Gohlke, H.; Luo, R.; Merz, Jr., K. M.; Onufriev, A.; Simmerling, C.; Wang, B.; Woods, R. J. Computat. Chem. 2005, 26, 1668.

47. Buch, V.; Martoňák, R.; Parrinello, M. J. Chem. Phys. 2006, 124, 204705.

48. Giannozzi, P.; Baroni, S.; Bonini, N.; Calandra, M.; Car, R.; Cavazzoni, C.; Ceresoli, D.; Chiarotti, G. L.; Cococcioni, M.; Dabo, I.; Dal, C. A.; de Gironcoli, S.; Fabris, S.; Fratesi, G.; Gebauer, R.; Gerstmann, U.; Gougoussis, C.; Kokalj, A.; Lazzeri, M.; Martin-Samos, L.; Marzari, N.; Mauri, F.; Mazzarello, R.; Paolini, S.; Pasquarello, A.; Paulatto, L.; Sbraccia, C.; Scandolo, S.; Sclauzero, G.; Seitsonen, A. P.; Smogunov, A.; Umari, P.; Wentzcovitch, R. M. J. Phys: Condensed Matter 2009, 21, 395502.

49. Blöchl, P. E. Phys. Rev. B 1994, 50, 17953.

5o. Holzwarth, N. A. W.; Tackett, A. R.; Matthews, G. E. Comp. Phys. Comm. 2oo1, 135, 329.

51. Becke, A. D. J. Chem. Phys. 1986, 85, 7184.

52. Perdew, J. P.; Burke, K.; Ernzerhof, M. Phys. Rev. Lett. 1996, 77, 3865.

53. Becke, A. D.; Johnson, E. R. J. Chem. Phys. 2007, 127, 124108.

54. Becke, A. D.; Johnson, E. R. J. Chem. Phys. 2007, 127, 154108.

55. Oganov, A. R.; Lyakhov, A. O.; Valle, M. Acc. Chem. Res. 2011, 44, 227.

56. Lyakhov, A. O.; Oganov, A. R.; Stokes, H. T.; Zhu, Q. Comput. Phys. Comm. 2013, 184, 1172.

57. Zhu, Q.; Oganov, A. R.; Glass, C. W.; Stokes, H. T. Acta. Cryst. 2012, B68, 215.

58. Gale, J. D.; Rohl, A. L. Mol. Simul. 2oo3, 29, 291.

59. Price, S. L.; Leslie, M.; Welch, G. W. A.; Habgood, M.; Price, L. S.; Karamertzanis, P. G.; Day, G. M. PhysChemPhys 2010, 12, 8478.

6o. Stone, A. J. J. Comput. Theo. E Comput. 2005, 1, 1128.

61. Togo, A.; Oba, F.; Tanaka, I. Phys. Rev. B 2008, 78, 134106.

62. Rodriguez-Carjaval, J. Physica B 1993, 192, 55.

63. Cruz-Cabeza, A. J.; Bernstein, J. Chem. Rev. 2014, 114, 2170.

64. Nyman, J.; Day, G. M. CrystEngComm, 2015, 17, 5154.

65. Case, D. H.; Campbell, J.E.; Bygrave, P. J.; Day, G. M. J. Chem. Theory Comput., 2016, 12, 910-924.

66. Kazantsev, A. V.; Karamertzanis, P. G.; Adjiman, C. S.; Pantelides, C. C. J. Chem. Theory Comput., 2011, 7, 1998. 
67. Wells, A. F. Discuss. Faraday Soc. 1949, 5, 197.

68. Milisajevic, B. S. PhD thesis, ETH Zürich, 1982.

69. Wireko, C. M. Sc. Thesis, Weizmann Institute of Science, 1985.

70. Davey, R. J.; Milisavijevic, B.; Bourne, J. R. J. Phys. Chem. 1988, 92, 2032.

71. Hussain, M.; Anwar, J. J. Am. Chem. Soc. 1999, 121, 8583.

72. Singh, M. K.; Sharma, S. K.; Banerjee, A. CrystEngComm 2o13, 15, 8493.

73. Srinivasan, K.; Sherwood, J. N. Cryst. Growth Des. 2005, 5, 1359.

74. Leiserowitz, L.; Lahav, M. Cryst. Growth Des. 2oo6, 6, 619.

75. Weissbuch, I.; Leiserowitz, L.; Lahav, M. Cryst. Growth Des. 2oo6, 6, 625.

76. Srinivasan, K.; Sherwood, J. N. Cryst. Growth Des. 2011, 11, 5010.

77. Anwar, J.; Chatchawalsaisin, J.; Kendrick, J. Angew. Chem. Int. Ed. 2oo7, 46, 5537.

78. Vorontsova, M. A.; Maes, D.; Vekilov, P. G. Farad. Disc. 2015, 179, 27.

79. Ectors, P.; Anwar, J.; Zahn, D. Cryst. Growth Des. 2015, 15, 5118.

8o. Ectors, P.; Wang, S.-T.; Chatchawalsaisin, J.; Zahn, D.; Anwar, J. Cryst. Growth Des. 2015, 15, 4026.

81. Glazer, A. M.; Lewis, J. G.; Kaminsky, W. Proc. R. Soc. London A 1996, 452, 2751.

82. Kaminsky, W.; Claborn, K.; Kahr, B. Chem. Soc. Rev. 2004, 33, 514.

\section{TOC GRAPHIC}

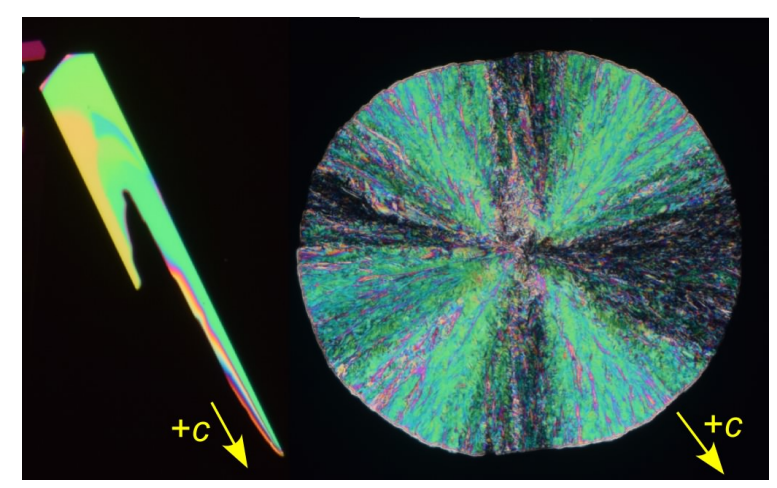


<smiles>Oc1cccc(O)c1</smiles>

$\mathrm{R}_{\mathrm{a}}$<smiles>Oc1cccc(O)c1</smiles>

$\mathrm{R}_{\mathrm{b}}$<smiles>Oc1cccc(O)c1</smiles>

$\mathrm{R}_{\mathrm{C}}$

Scheme 1. Conformations of resorcinol molecule.

$50 \times 14 \mathrm{~mm}(600 \times 600 \mathrm{DPI})$ 


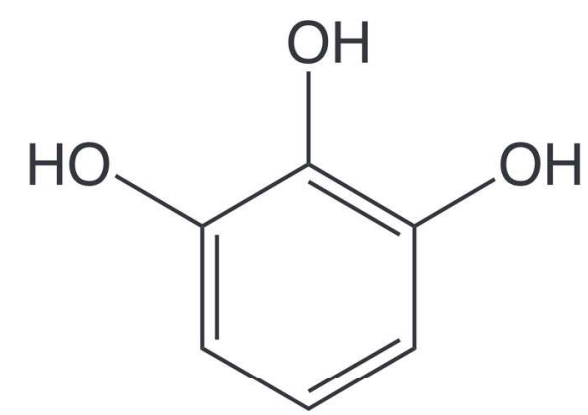

pyrogallol

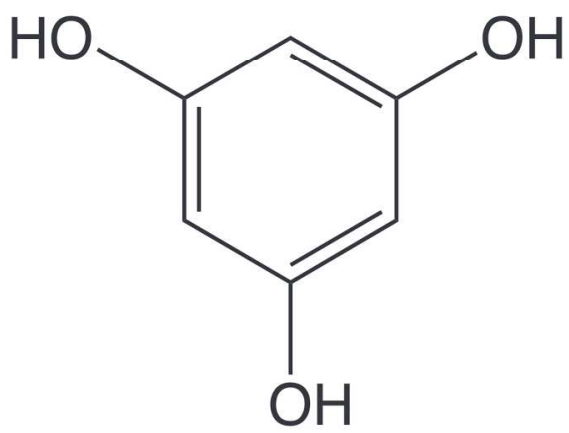

phloroglucinol

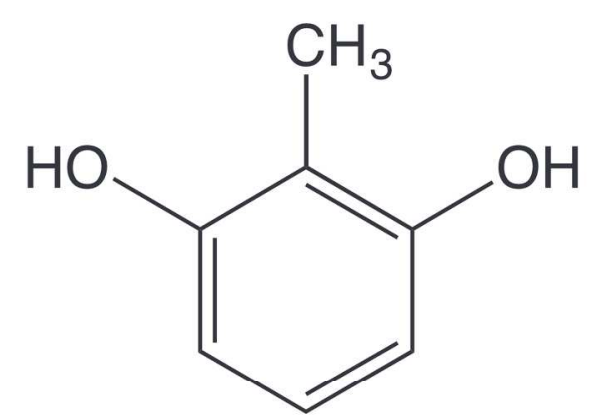

2-methylresorcinol

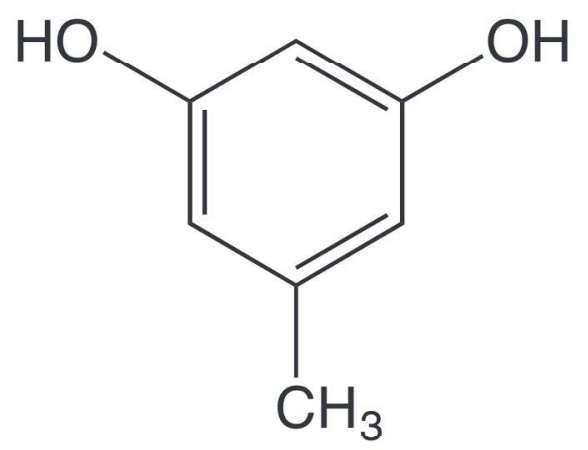

\section{5-methylresorcinol (orcinol)}

Scheme 2. Tailor made additives used to establish polar direction of $\beta$ resorcinol. $96 \times 83 \mathrm{~mm}(600 \times 600 \mathrm{DPI})$ 

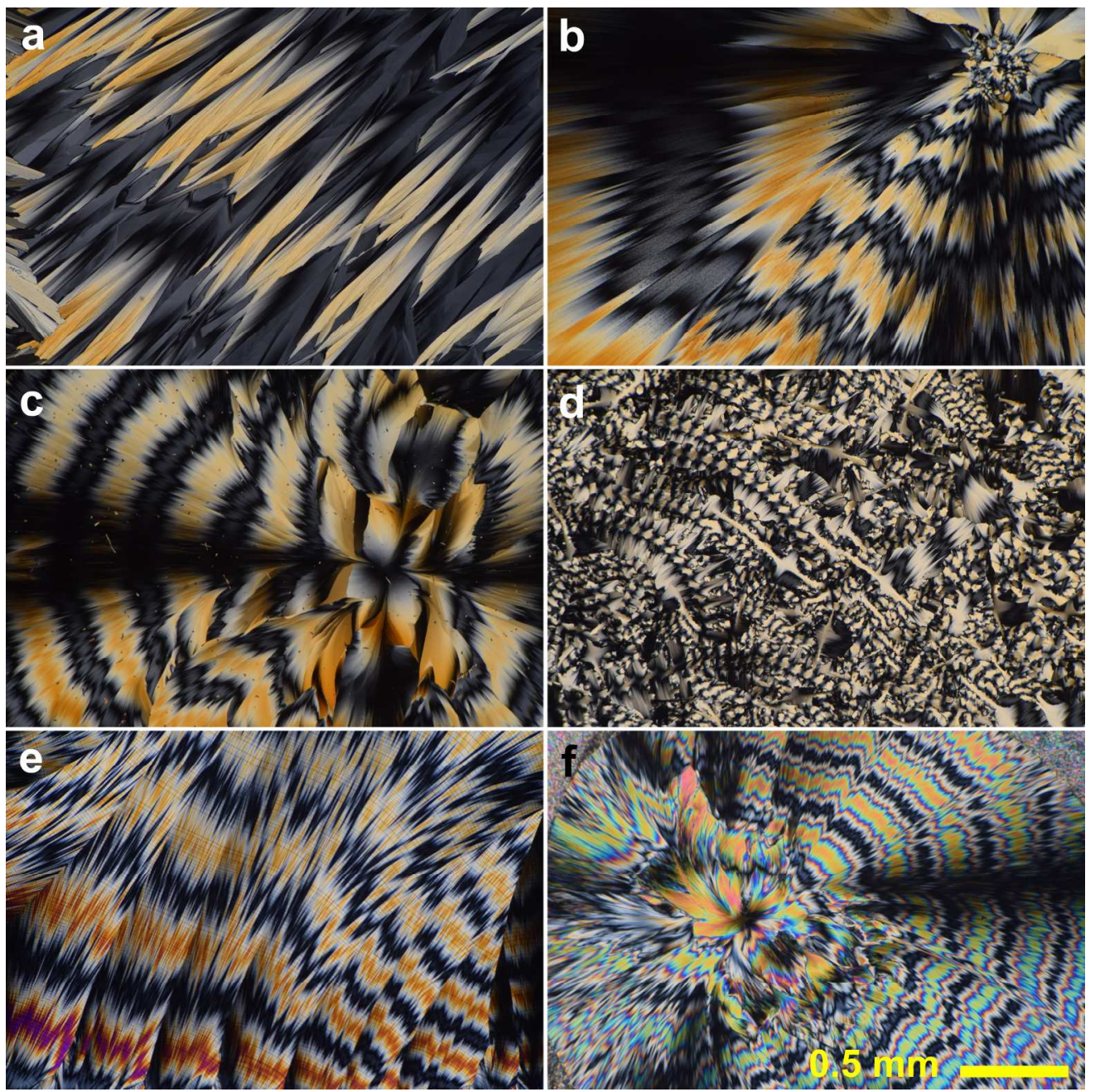

Figure 1. Polarized light optical micrographs of the $\varepsilon$ orm. (a) Irregular banded spherulite formed at $80{ }^{\circ} \mathrm{C}$. (b) Banded spherulite formed at $75^{\circ} \mathrm{C}$, showing two twist periods. (c) Banded spherulite formed at $51^{\circ} \mathrm{C}$. Irregular pattern with small areas of banded spherulites formed at $35^{\circ} \mathrm{C}$ (d). Banded spherulites formed at room temperature in the presence of $20 \mathrm{wt}$ \% 2-methylresorcinol (e) and 5-methylresorcinol (f). 
1

2

3

4

5

6

7

8

9

10

11

12

13

14

15

16

17

18

19

20

21

22

23

24

25

26

27

28

29

30

31

32

33

34

35

36

37

38

39

40

41

42

43

44

45

46

47

48

49

50

51

52

53

54

55

56

57

58

59

60

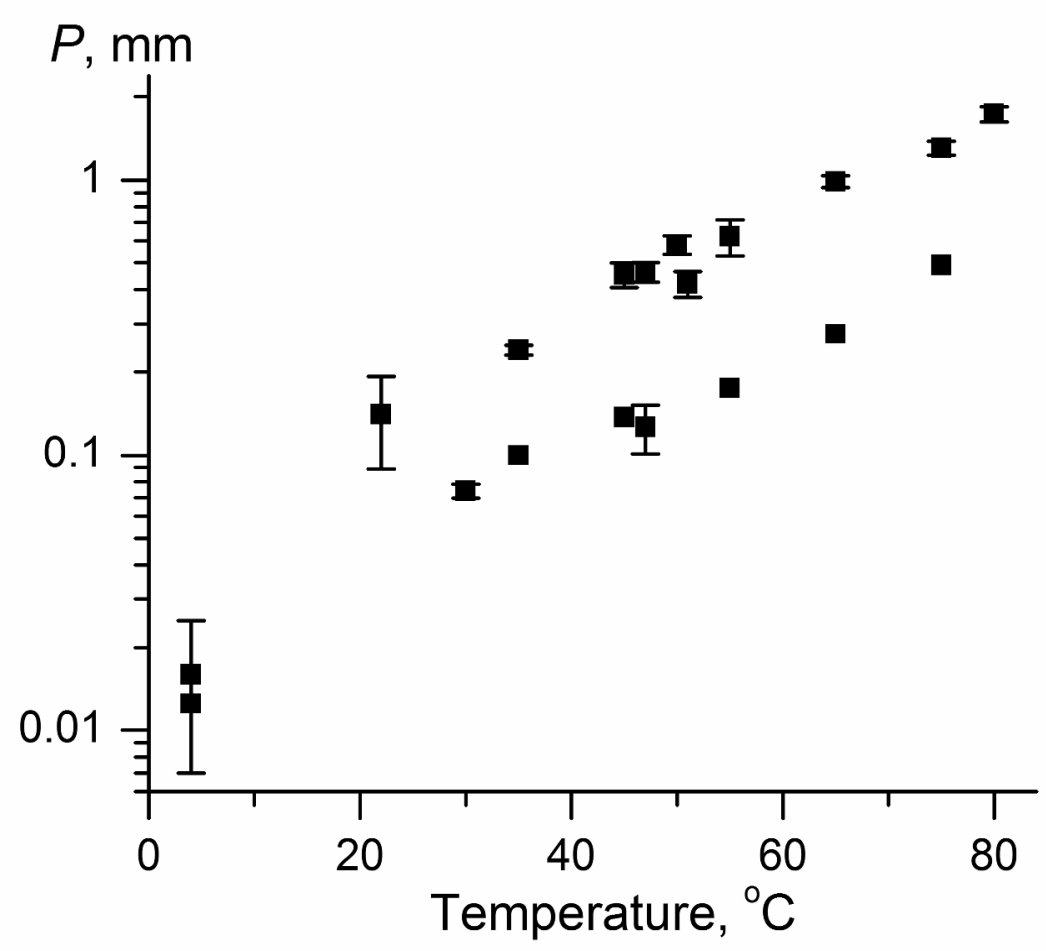

Figure 2. Twist period, $P$, of $\varepsilon$ as a function of growth temperature, $T$. Note two populations of twist periods for $T>22^{\circ} \mathrm{C}$.

$541 \times 414 \mathrm{~mm}(150 \times 150 \mathrm{DPI})$ 


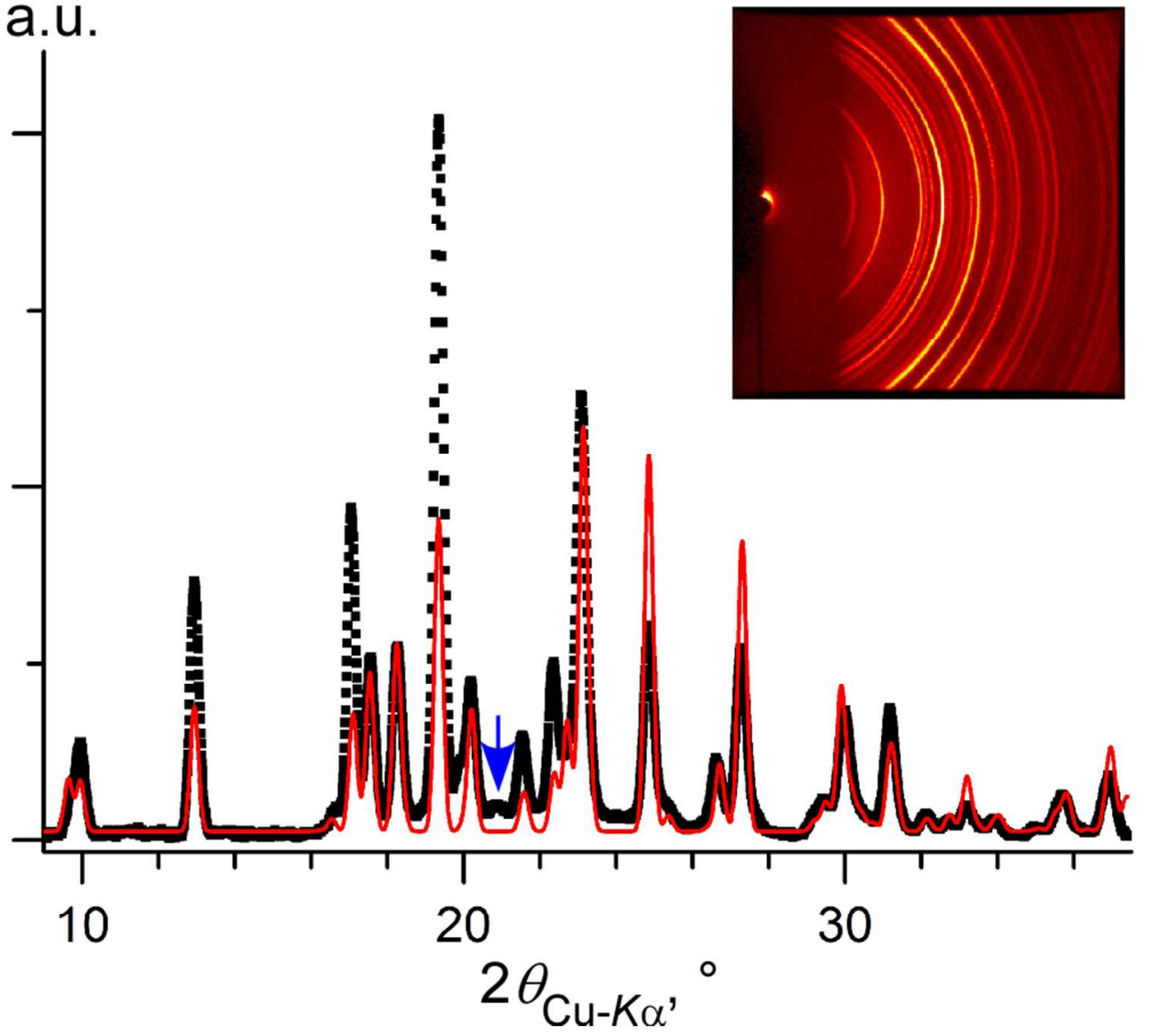

Figure 3. 2D diffraction pattern (inset) and corresponding integrated intensities of a powder sample of the $\varepsilon$ form (black dots). Sample contains 5 wt.\% $(2 S, 3 S)$-(-)-tartaric acid. Red line corresponds to the simulated diffraction pattern. The blue arrow points to the strongest maximum of the $\beta$ form.

$88 \times 76 \mathrm{~mm}(300 \times 300 \mathrm{DPI})$ 
1

2

3

4

5

6

7

8

9

10

11

12

13

14

15

16

17

18

19

20

21

22

23

24

25

26

27

28

29

30

31

32

33

34

35

36

37

38

39

40

41

42

43

44

45

46

47

48

49

50

51

52

53

54

55

56

57

58

59

60

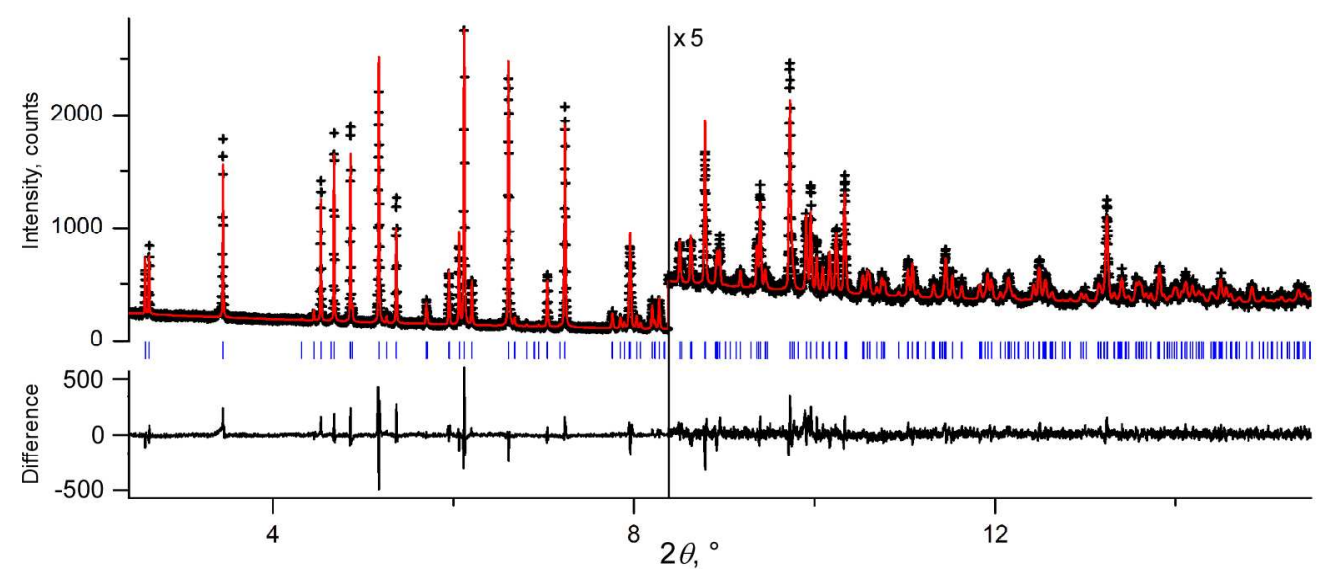

Figure 4. Rietveld refinement of high-resolution synchrotron powder diffraction for $\varepsilon$ resorcinol sample containing 5 wt. $\%(2 S, 3 S)-(-)$-tartaric acid. Observed (black crosses) and calculated (red line). $R_{w p}=7.74$ $\%, X^{2}=0.838$. Data were collected at the ESRF at a wavelength of $0.41064 \AA$ and at a temperature of 200 $\mathrm{K}$. The lower trace shows the difference curve.

$$
186 \times 80 \mathrm{~mm}(300 \times 300 \mathrm{DPI})
$$




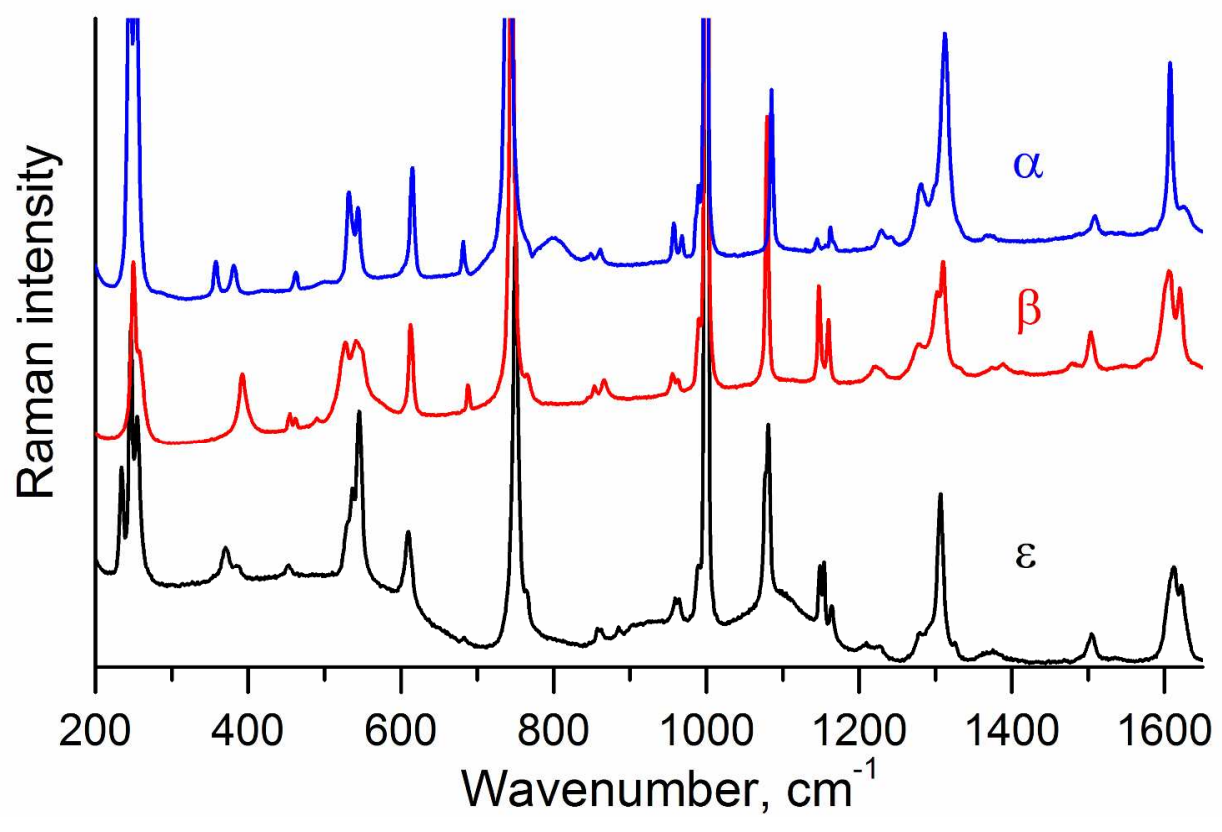

Figure 5. Raman spectra of resorcinol polymorphs.

$541 \times 414 \mathrm{~mm}(150 \times 150 \mathrm{DPI})$ 


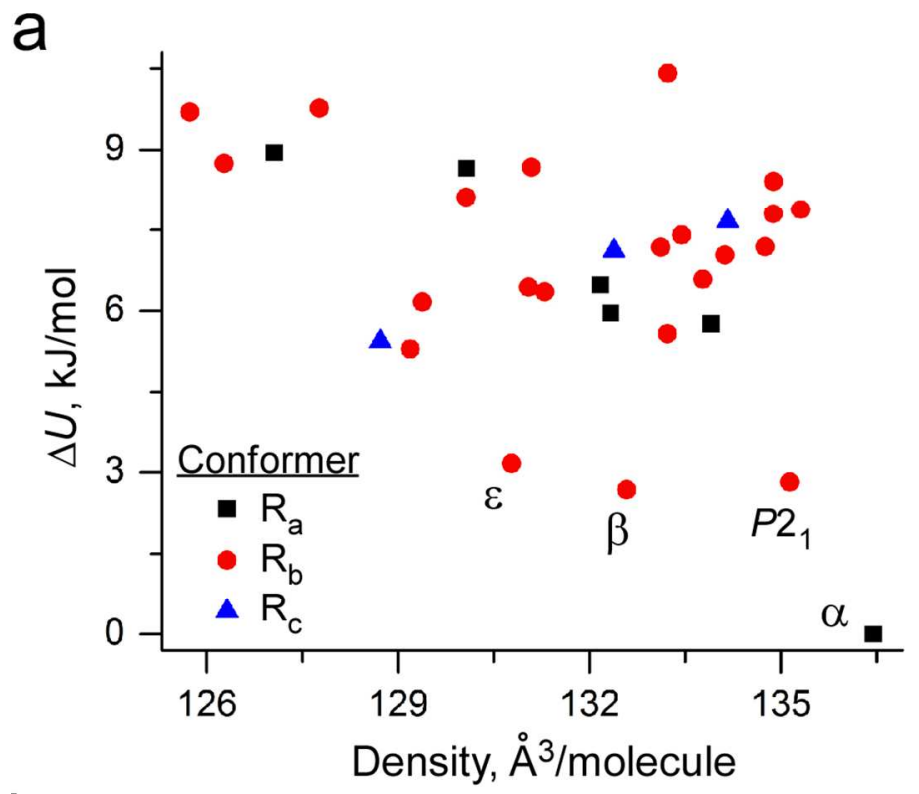

b

Figure 6. Energy comparison for various resorcinol polymorphs. (a) Lattice energy vs volume plot for all low energy structures found in the present study, as calculated at the B86b-XDM level of theory. (b) Helmholtz free energy differences vs temperature for selected polymorphs.

\section{$83 \times 143 \mathrm{~mm}(300 \times 300 \mathrm{DPI})$}


a

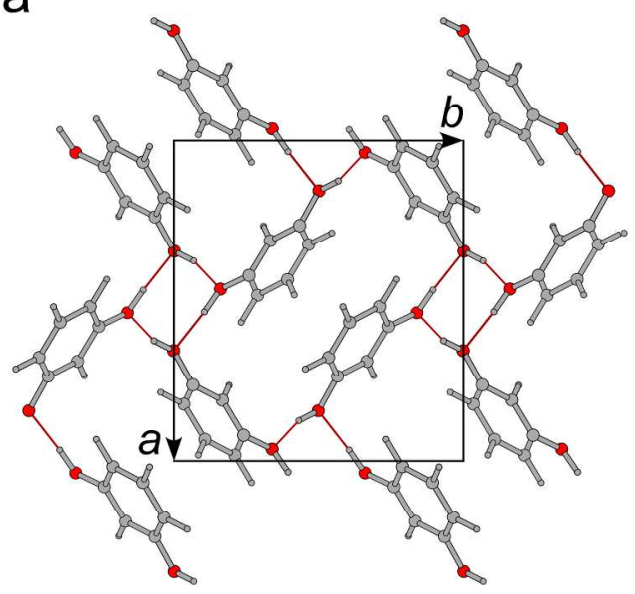

C

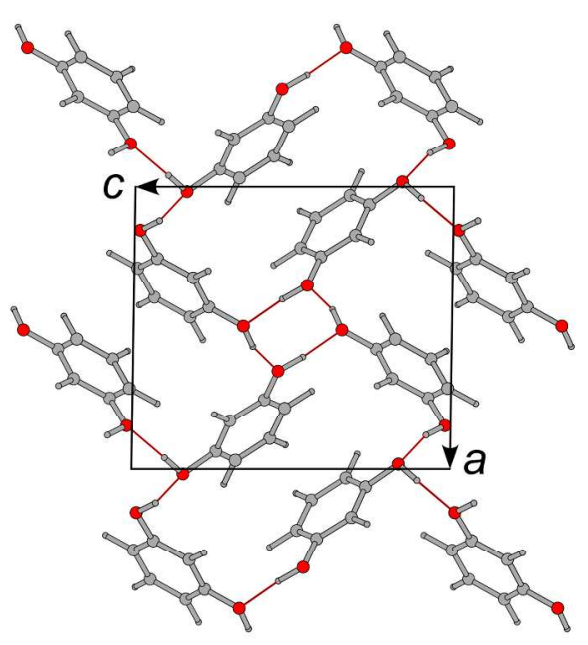

b

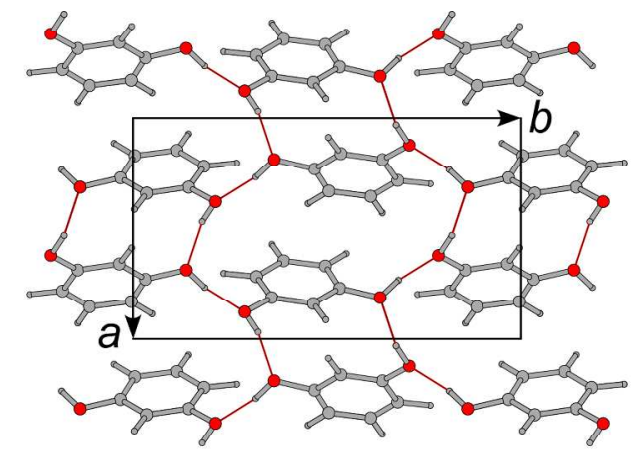

d

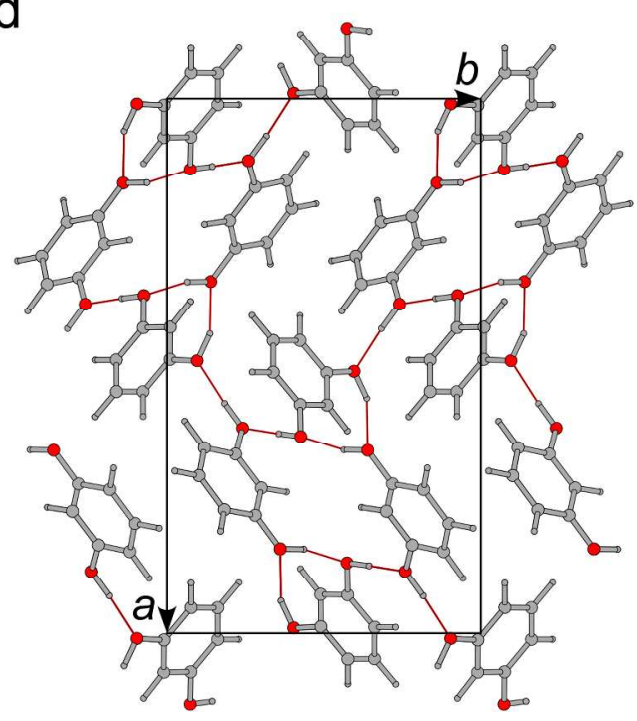

Figure 7. Resorcinol crystal structures (a) $a$, (b) $\beta$, (c) $\varepsilon$, and (d) the $P 2_{1}$ phase. The views in each case are such that the molecules in any one structure project equal areas onto the plane of the page.

$204 \times 210 \mathrm{~mm}(300 \times 300$ DPI $)$ 
Figure 8. Projections of crystal structures of $a(a)$ and $\beta(b)$ resorcinol normal to the polar axes on (010) and (100) planes, respectively. For $a$ resorcinol, the 5-methylresorcinol and 2-methylresorcinol molecules can bind to the $+c$ and $-c$ directions, respectively, and subsequently block them. For $\beta$ resorcinol, 5methylresorcinol and 2-methylresorcinol molecules can bind to the $-c$ and $+c$, respectively.

$529 \times 297 \mathrm{~mm}(72 \times 72$ DPI $)$ 

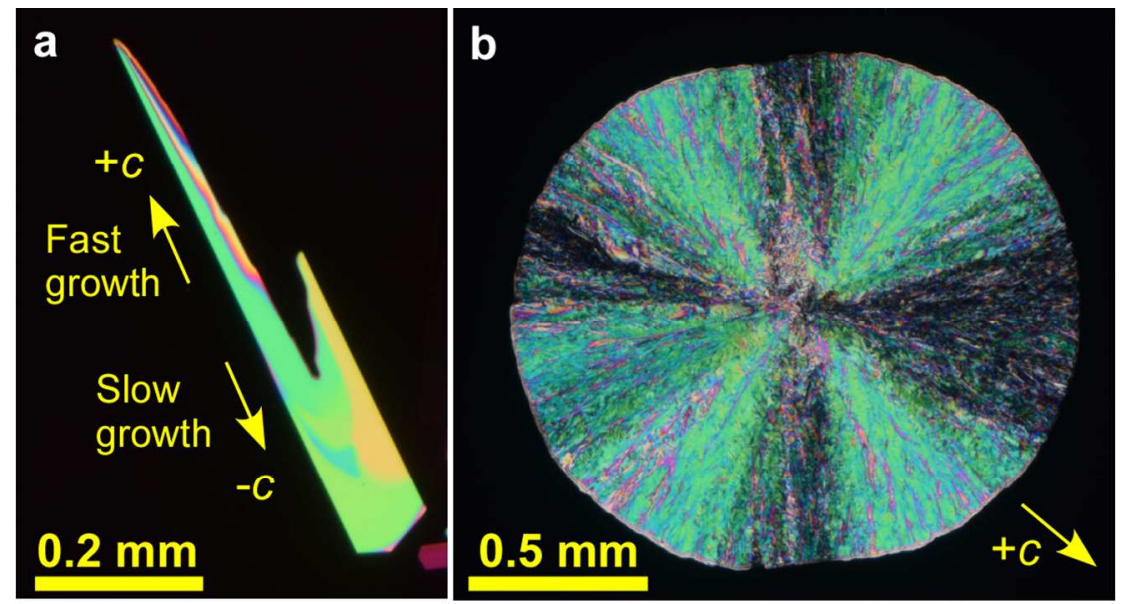

C

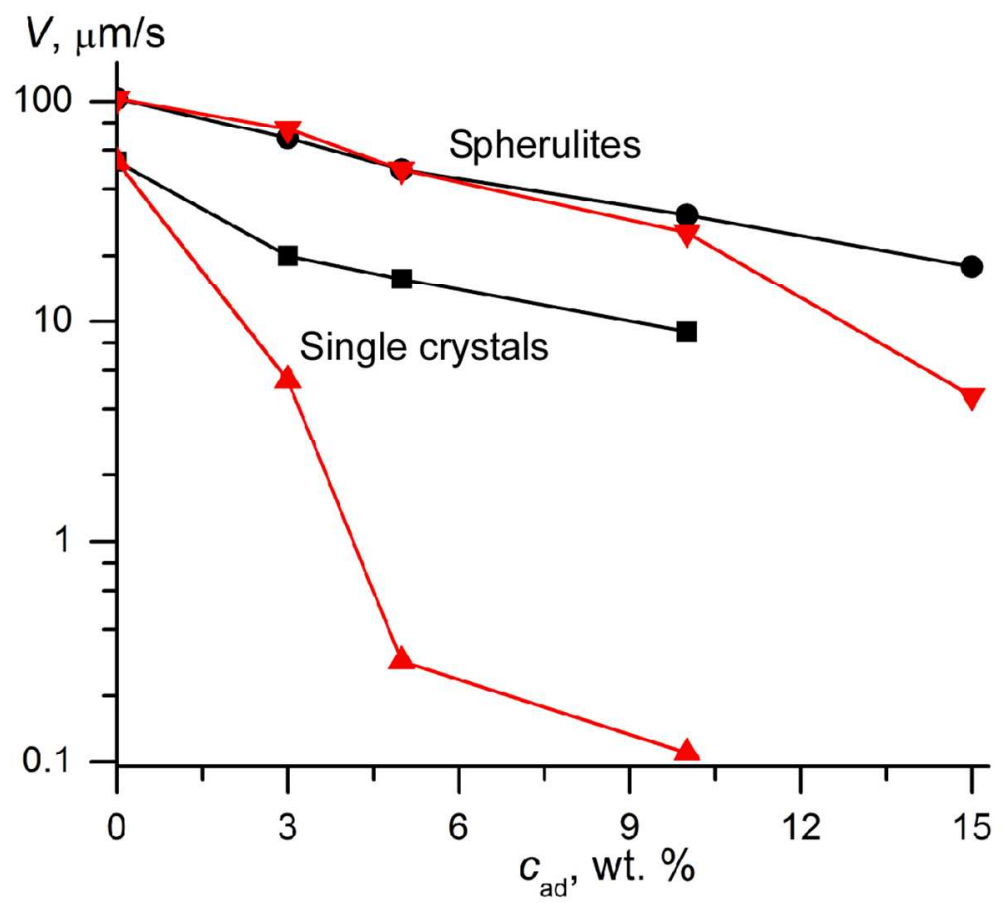

Figure 9. $\beta$ resorcinol single crystals (a) and spherulites (b) growing from the melt close to the melting point and at the room temperature, respectively. Admixture of 5-methylresorcinol $10 \mathrm{wt}$.\%. c. Effect of 2methylresorcinol (red symbol and lines) and 5-methylresorcinol (black symbol and lines) admixture on the growth rate of $\beta$ resorcinol in the faster $+c$ direction in single crystals formed at supercooling of $0.5^{\circ} \mathrm{C}$ (up triangles and squares) and spherulites formed at room temperature (down triangles and circles).

$99 \times 141 \mathrm{~mm}(300 \times 300 \mathrm{DPI})$ 


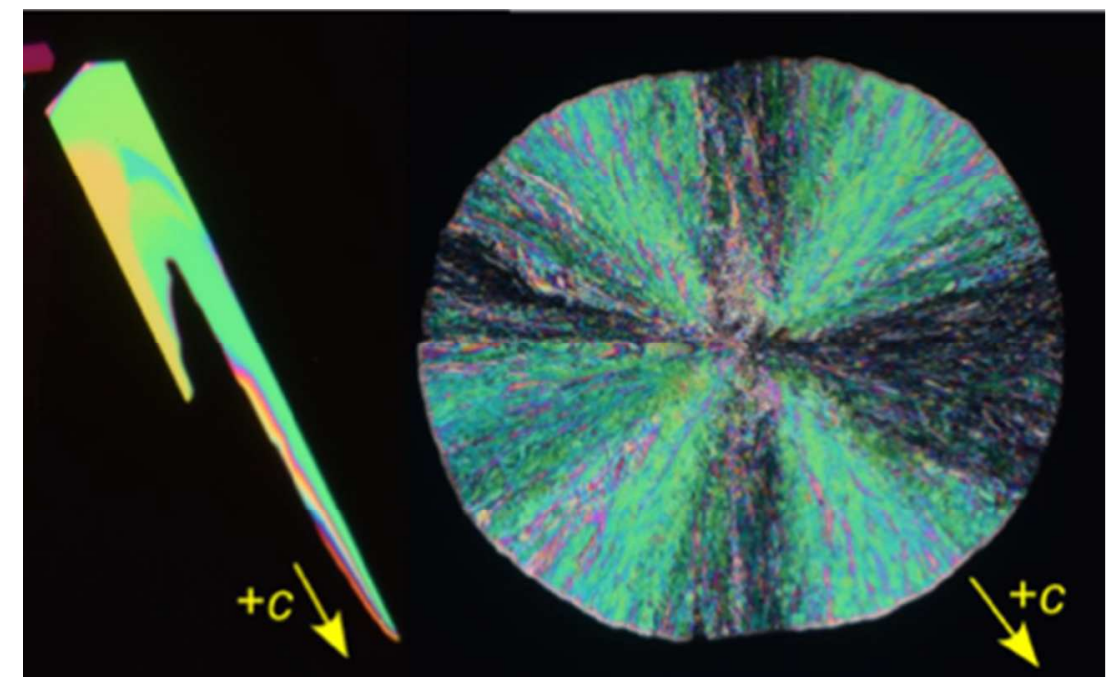

[Table of Contents Graphic]

$146 \times 90 \mathrm{~mm}(72 \times 72$ DPI $)$ 